\title{
TOWARD A METHODOLOGY OF DEFINING STAKEHOLDERS AND THEIR ROLES IN URBAN UPGRADING PROJECTS
}

\author{
Ahmed Abdalla Abdel-Ghany \\ Associate Professor Faculty of Urban and Regional Planning, \\ Cairo University
}

(Received February10, 2007 Accepted March 14, 2007)

\begin{abstract}
In urban upgrading projects, although many experiences shows efforts in the application of participatory planning concept, yet, the definition of participative parties (stakeholders) and their roles in the project does not take the enough attention. The present research adopts the following statement: "definition of stakeholders and their roles in urban upgrading projects must be achieved accurately in the first stage of the project, and the process must take into account potentials and skills of each stakeholder. The research aims at soliciting indicators and principles which can help in the definition of participative parties in urban upgrading projects. The research is consisted of three main parts. In the first part, a theoretical review of stakeholders and their potentials and skills is made. The second part includes an analytical study of many participatory upgrading projects in Egypt. The third part contains solicited indicators and principles which can help in designing a more realistic and reliable methodology for participatory planning in urban upgrading projects.
\end{abstract}
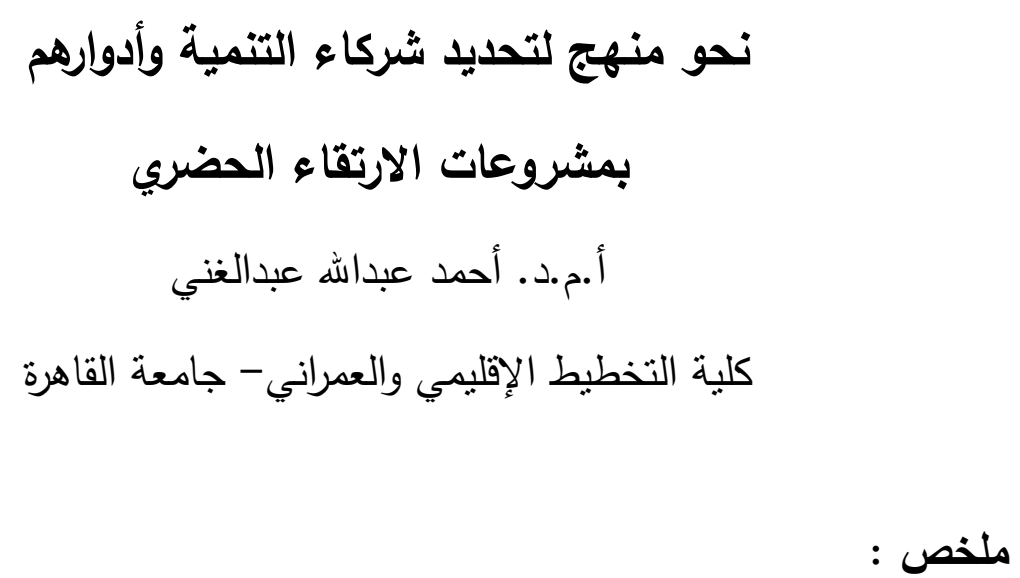

تعتبر قضية تحديد شركاء التتمية وأدوارهم في مشروعات الارتقاء الحضري من القضـايا الهامـة التي تحتاج إلى مزيد من البحث والتتقيب، فبالرغم من أن التجارب السابقة تعكس جهوداً في هذا المجال إلاء أن عملية التحديد غالبا ما تتم بشكل سريع وتأخذ وقت واهتمام محدود نسبياً مقارنة بالأعمال والأنشطة الأخرى بالمشروع، وبؤكد هذا البحث على الفرضية القائلة بأن تحديد شركاء التتمية (الحكومة المركزية، 


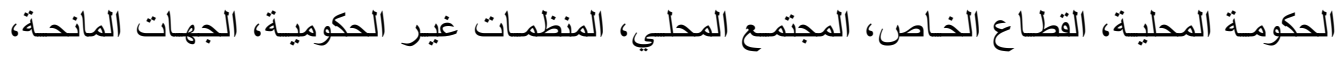
المخططون والمصممون العمرانيون ...إخخ) وأدوارهم لابد أن يتم بدقة في بداية المشروع من خلال إطار

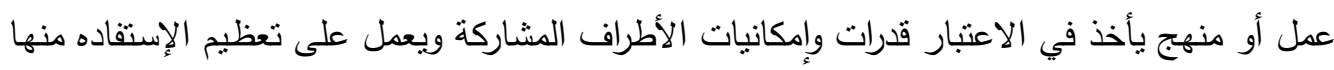

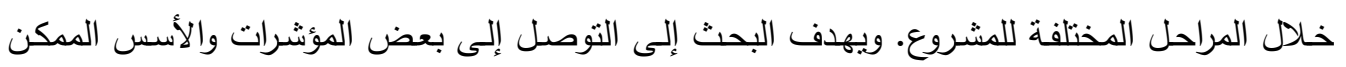

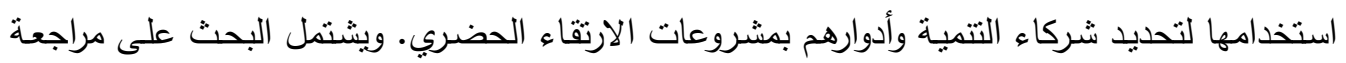

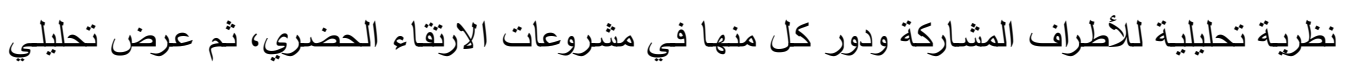

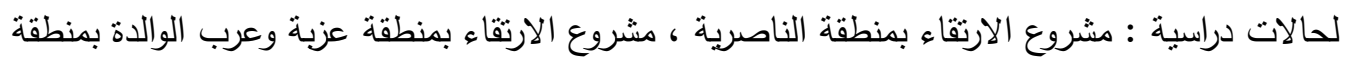

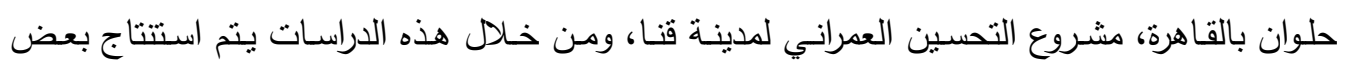

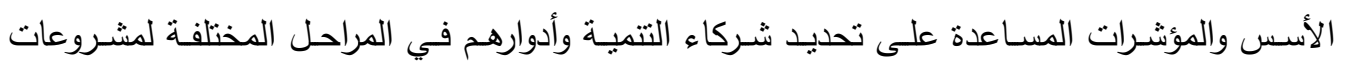
الارتقاء الحضري.

\section{الإثكالية والتساؤلات البحثية:}

في معظم الدول النامية يعيش ما يقرب من نصف سكان المدن الرئيسية من ذوي الدخل المنخفض في

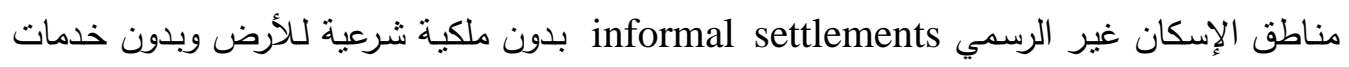

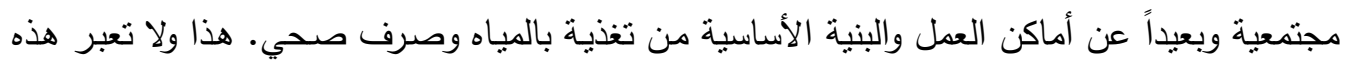

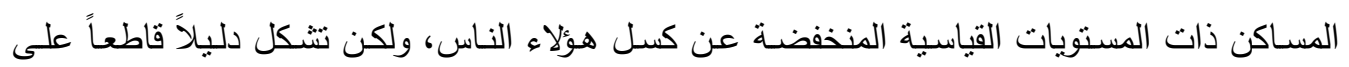

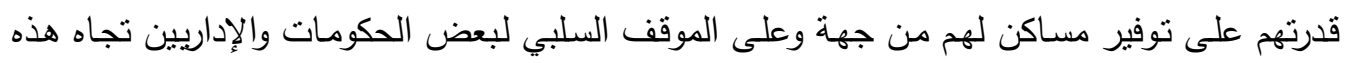

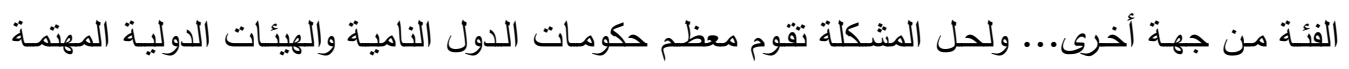
بتحسين الأحوال المعيشية للفقراء بالارتقاء بهذه المناطق والحفاظ على الرصيد السكني لهذه الفئة التي

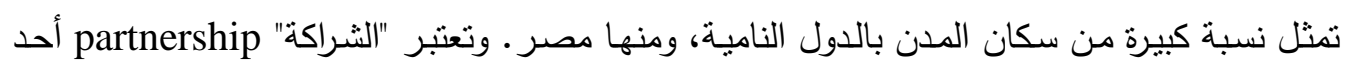

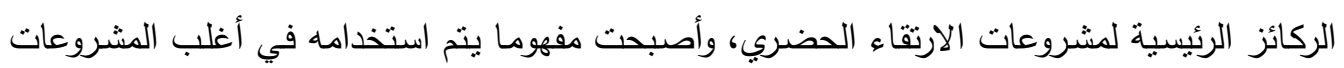

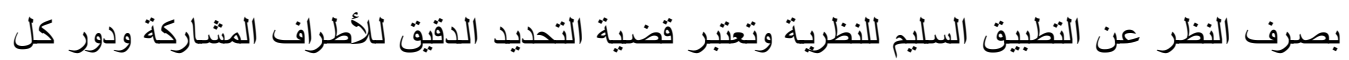

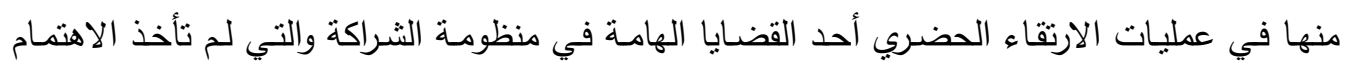

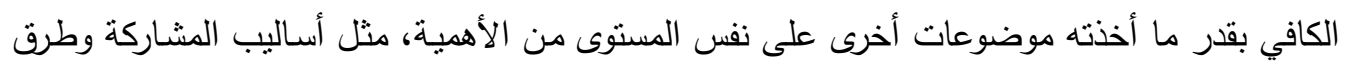

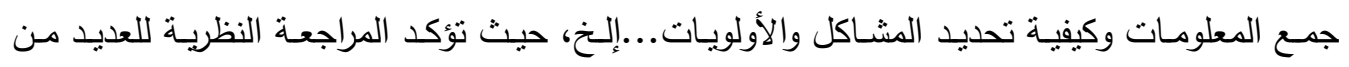
الششروعات إن العطلية التخطيطية planning process لمعظم المشروعات السابقة بداية من الإعلان عن مشروع الارتقاء وحتى عمليات المتابعة والصيانة لا تشتمل على خطوات واضحة لتحديد شركاء

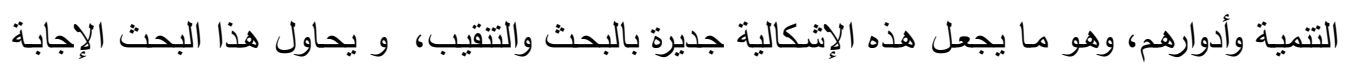


] مـا هي الجهات والأطـراف المشـاركة في مشـروع الارتقاء الحضـري؟ ومـا هي الأدوار

المختلفة لكل جهة أو طرف؟

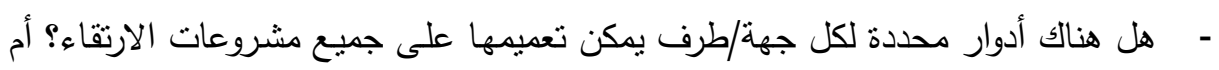
أن تحديد الأدوار ينت لكل مشروع على حدة وفقا لأهدافه وظروفه؟

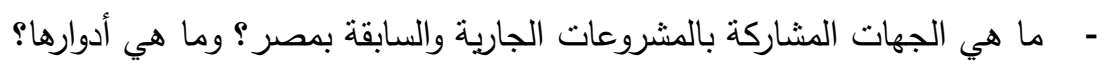

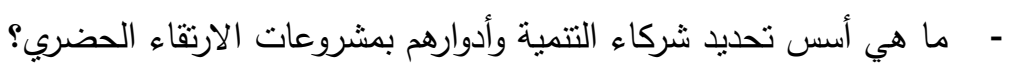

\section{• فرضية البحث :}

يتبنى البحث الفرضية القائلة بأن الثراكة الفاعلة في مشروعات الارتقاء الحضري لا تتحصر في العلاقة

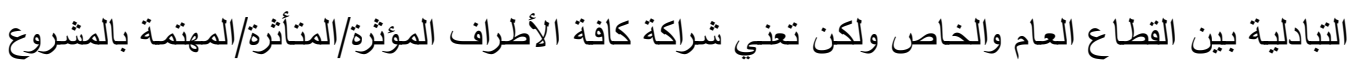

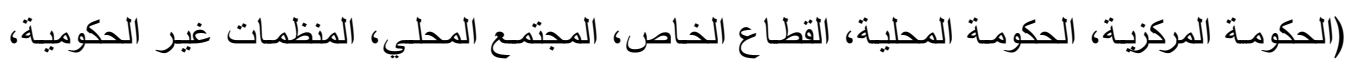

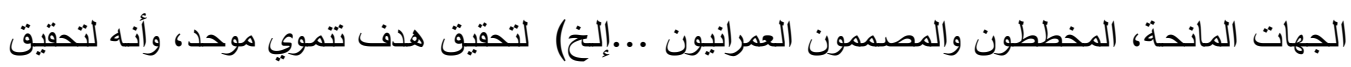
هذا الهدف لابد من تتظيم العمل بين هذه الجهات/الأطراف وتحديد دور كل منهم في جميع مراحل النتمية.

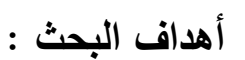

يهدف البحث إلى إلقاء الضوء على أهمية شراكة كافة أطراف الهتهـع في دعم مشروعات الارتقاء الحضري، ويهدف كذلك إلى التوصل إلى بعض المؤشرات والأسس المككن استخدامها لتحديد شركاء

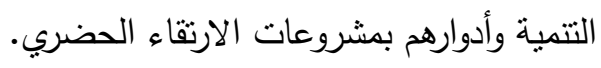

\section{منهج البحث :}

يعتمد البحث على المنهج النظري الاستقرائي ومنهج دراسة الحالة، ويتكون من خمسة أجزاء رئيسية هي

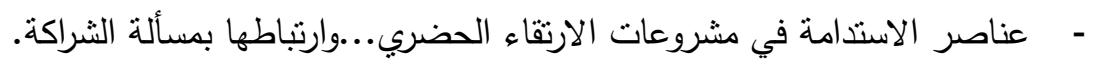
ل الحاجة الماسة للشراكة بمشروعات الارتقاء الحضري.

] مراجعة نظرية تحليلية للأطراف المشاركة ودور كل منها في مشروعات الارتقاء الحضري.

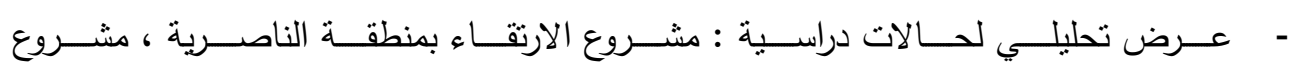

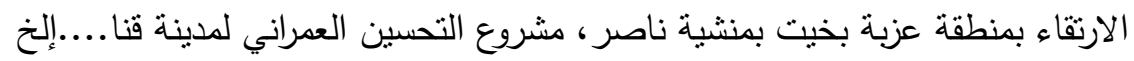
] استتناج الأسس والمؤشرات المساعدة على تحديد شركاء التتمية وأدوارهم في المراحل المختلفة لمشروعات الارتقاء الحضري. 


\section{1 - عناصر الاستدامة في مشروعات الارتقاء الحضري...وارتباطها بموضوع الشراكة}

لتحقيق الأهداف المرجوة من مشروعات الارتقاء الحضري فإنه ينبغي تحقيق التتمية المستدامة بمفهومها

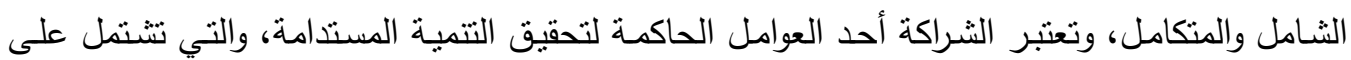
أربعة عناصر أساسية ترنبط بموضوع الثراكة بأثكال ونسب مختلفة على النحو التالي:(1)

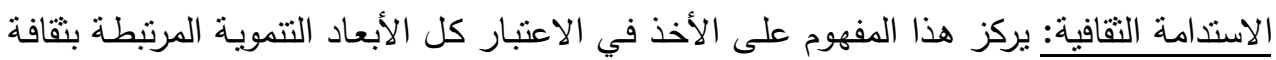

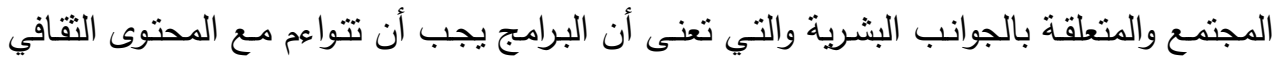

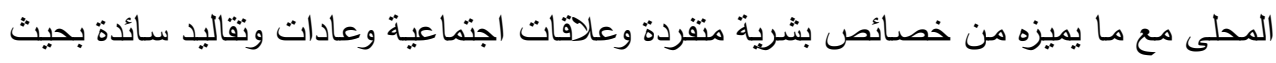

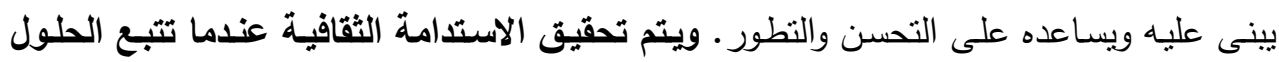
والمقترحات للرغبات الحقيقية للمجتمع، والذي يتأنى من خلال التعايش مع السكان ومشاركتهم في التئي صناعة القرارات الخاصة بييئته.

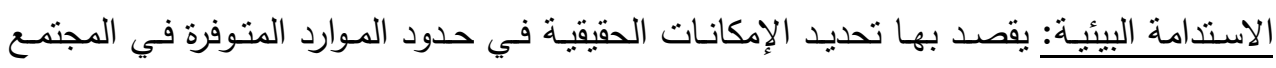
وحسن استغلالها بما يضمن تحقيق أهداف التتمية مع الحفاظ على التوازنات المرفولوجية والمناخية والجيولوجية والعمرانية والتي تحفظ التوازن الإيكولوجي للأجيال المستقبلية. وتتركز الاستدامة البيئية من هذا المنطلق على الفهم المتعلق للمحتوى البيئي للمجتمع المحلى والخصائص التي شكلت التصني

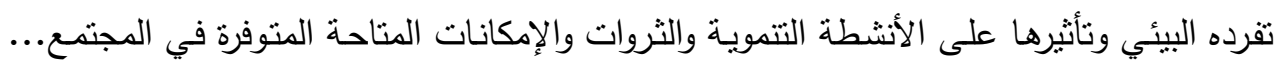
ويتم تحقى الاستدامة البيئية من خلال تحسين الظروف المعيشية للسكان ورفع مستوى الحياة

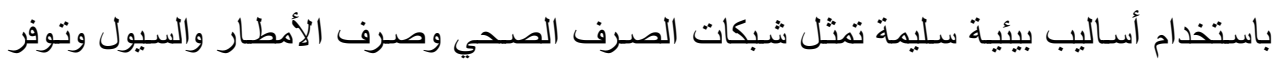

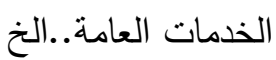

الاستدامة السياسية والمؤسسية والتتظيمية: ترتبط بعدد من الجوانب، يتعلق الجانب الأول منها

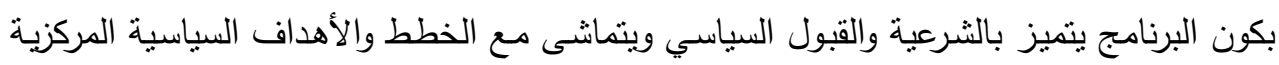

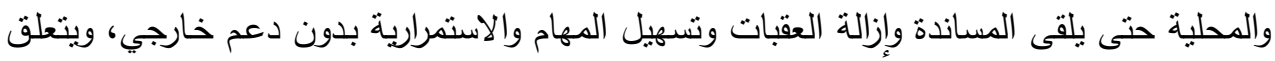
الجانب الثاني منها بالقبول على مستوى المجتمع المحلى وتتظيماته المختلفة والتي تتضمن مشاركة

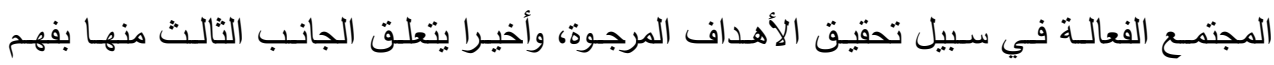
المؤسسات الحكومية والخاصـة والتتظيمات المجتمعية وهي التي تساهم في التتمية وتعبئة الموارد

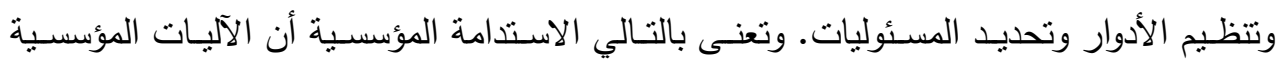

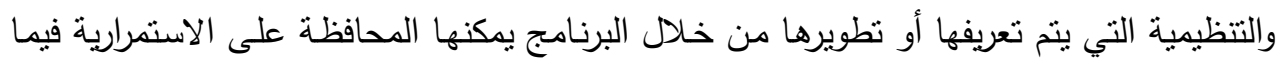

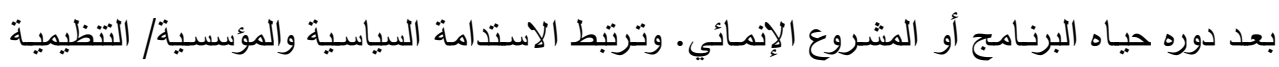
بالأنشطة التي تؤدي إلى تقوية النمط المجتمعي للعلاقات المؤسسية والتنظيمية والإنسانية السائدة في المجتمع المحلى وتتظيم الجهود المشتركة واكتسابها لقدرة اكبر على مواجهه وحل المشاكل. لقدئل 
وتتأتي مـن وجـود هيكل يجمـع المجتمـع مـع الحكومـة واعتراف متبـادل مـن الجهتين بعضهمها

البعض والمساندة في انجاز الأعمال والمشروعات التنموية لرفع مستوى المناطق العمرانية.

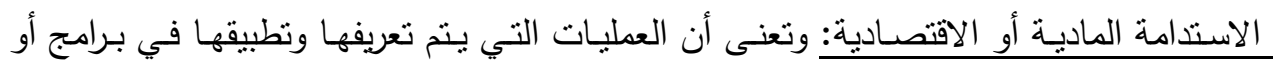
مشاريع التتمية يمكنها أن تستمر بدون إمداد مالي خارجي. وتعتمد الاستدامة المادية على التحليل

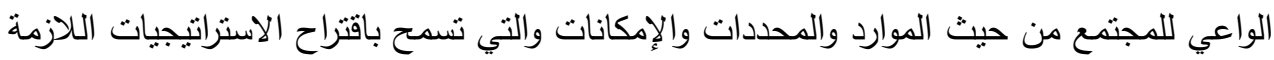

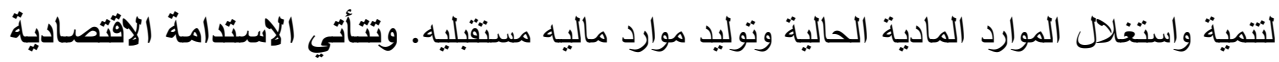
من إيجاد مصادر جديدة للاخل الإجمالي من خلال المشروعات الصغيرة والتدريب على الإعمال

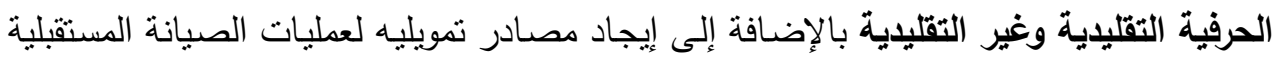

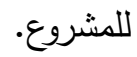

r - مشروعات الارتقاء الحضري.... والحاجة الماسة للشراكة

تثـير نتـائج تجـارب مشـروعات الارتقاء الحضـري إلى أن الششروعات التي اعتمـت على التطـوير العمراني physical improvement هنفرداً قلما استطاعت تحقيق نتائج إيجابية على الددى الطويل، إذ أن تلك الحلول التي تعتمد على إمداد المستوطنات ببعض المرافق الأساسية والخدمات العامـة لم تسنطع في أكثر الأحيان التصدي لمشاكل التدهور العمراني، فضعف الموارد التي يعتمد عليها السكان

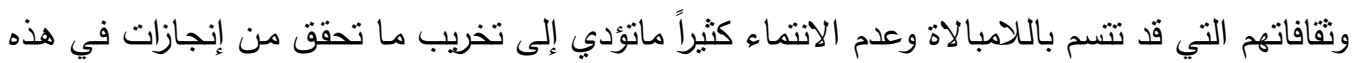

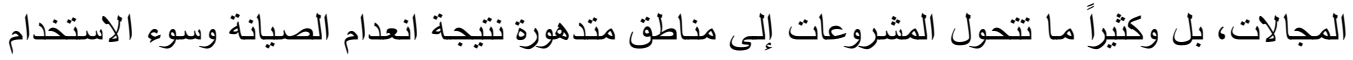

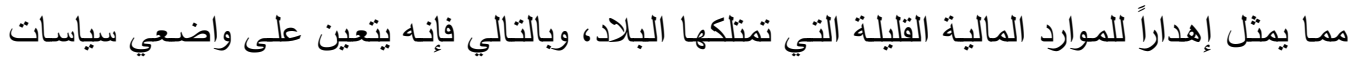

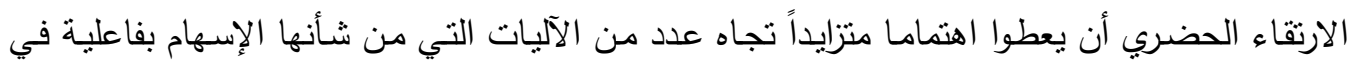

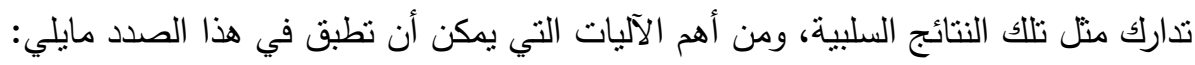
• إثراك القطاع الخاص والتعاوني والمنظمات غير الحكومية وغيرها من القوى الاقتصادية القادرة

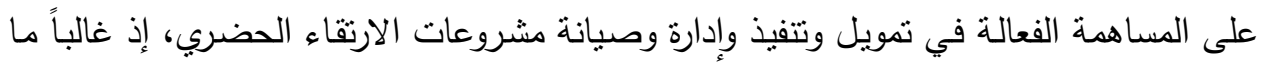

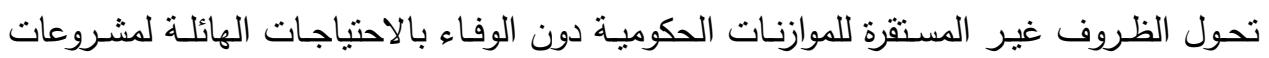
البنية الأساسية المحلية على نحو ملائم.

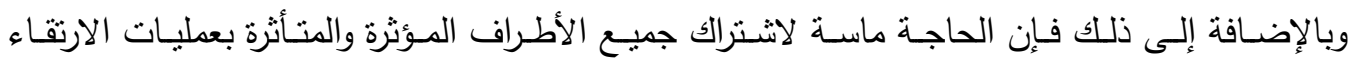
الحضري وذلك لما يلي:

إن عملية الارتقاء الحضري هي عملية مستمرة وتتطلب التتسيق الفعال بين جهود جميع

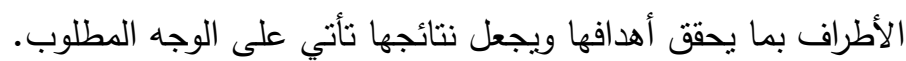

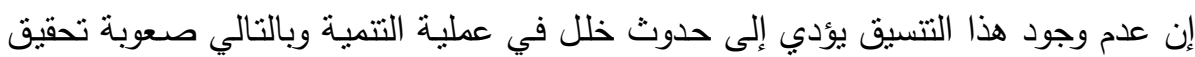
أهدافها المختلفة، مما ينعكس بالسلب على المدينة في شكل إثكاليات معقدة يعاني منها 
السكان، فتتحول أدوار القطاعات من عنصر فعال في تحقيق عملية التتمية إلى مصدر

رئيسي للمشكلات المتفاقمة.

إنه وفي ظل الضغط الذي أصبحت تعاني منه الحكومات مع الزيادة السكانية الرهيبة التي

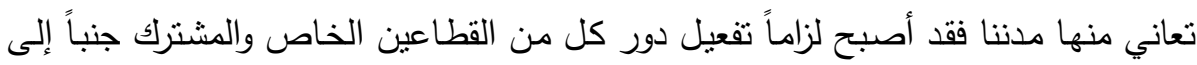

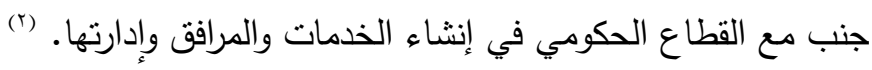

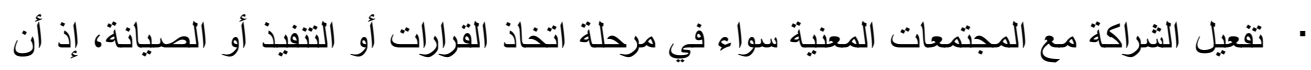
ذللك من شأنه خلق الثعور بالملكية المحلية لأصول البنية الأساسية مما يحقق مزايا عديدة أهمها:

المسـاعدة على تحديد الأولويـات ولا سبما في الجـالات التي يصسب تقريرهـا من خـلال التحليل الاقتصادي. المساعدة على جودة التشغيل والصيانة؛ لأنه من النادر أن يكون في الإمكان الاعتماد على الإلى

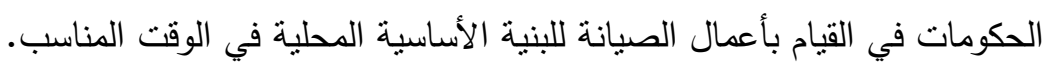

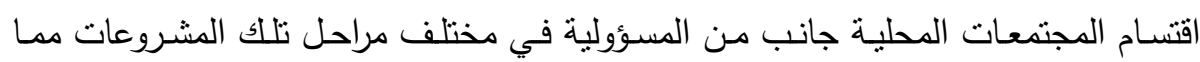

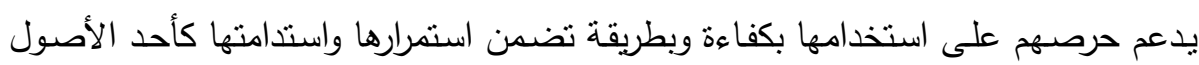
الحضرية.

• العمل على تطبيق "سياسات التتمية الحضرية الثاملة" التي تتضمن حزمة متكاملة من السياسات

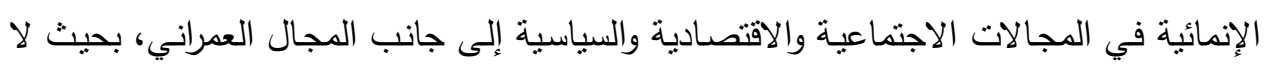

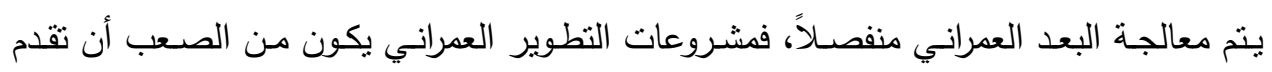

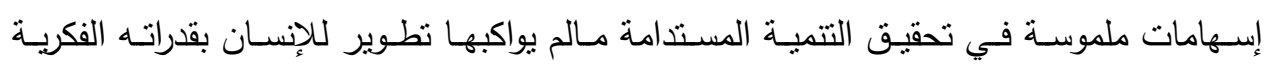

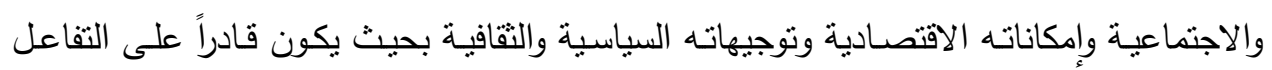
الإيجابي مع مختلف القوى الحضرية. (s)

\section{r- ب - منظومة الثراكة الفاعلة}

r-

ظهر مفهوم الثراكة مع مفاهيم أخرى مثل الخصخصة أنمارئ privatization في بداية الثمانينات، وسرعان

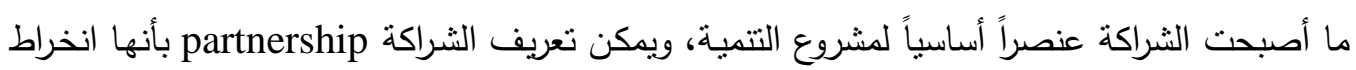
كافة أطراف التتميـة - بنـاءاً على وعي بالقضية ومصالح الأطراف المختلفة - في عمليات تفاوضية مستمرة في عملية صناعة القرار واتخاذه يترتب عليها نوع من الاتفاقات المحددة لتوزيع كافة الأدوار

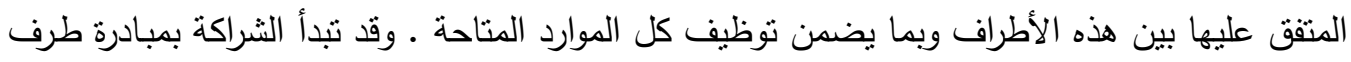

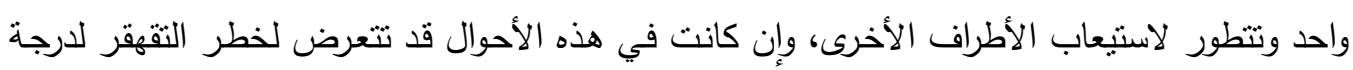


المشاركة فقط، وقد تبدأ بمبادرة أكثر من طرف، ولكنها تأخذ شكلها الحقيقي والكامل مع ارتفاع درجات

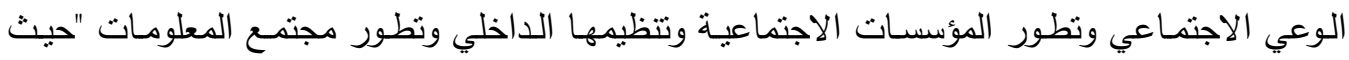

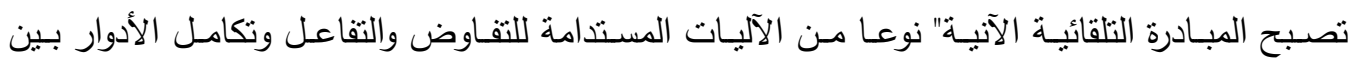
الأطراف المختلفة، والتتي تعكس التعاون والتقاء المصالح أو تتاقض المصالحسالح، وبما يجسد في في مجملة

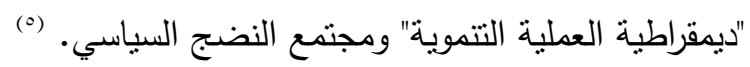

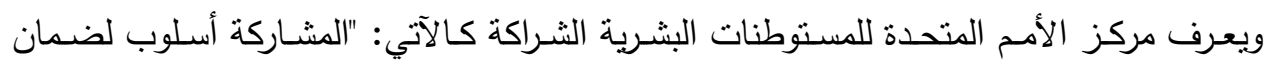
الاستغلال الأمثل للمزايا النسبية للعاملين المختلفين بطريقة المساندة المتبادلة، أي تحقيق الانسجام بين نقاط القوة والضعف لدى القطاع العام والتجاري والقطاع الثالث بحيث تستغل نقاط القوة أقصى استغلال،

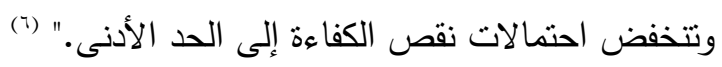

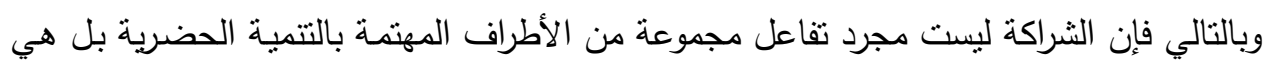

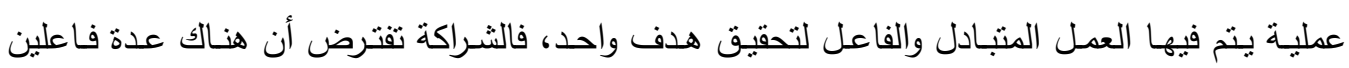

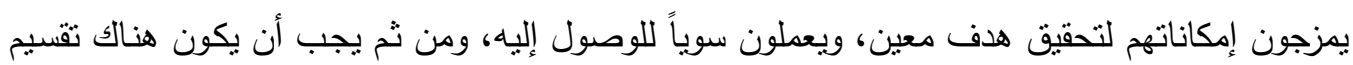

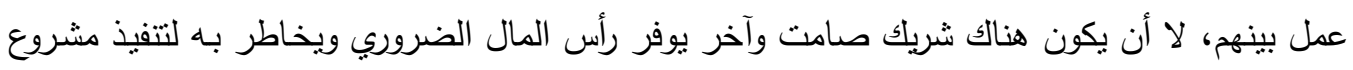
(v)

وقد أرتبط مفهوم الثراكة بمفهوم التتمية المستدامة عندما اتفق زعماء العالم في قمة الأرض التي عقدت في ريو دي جينيرو عام ب9919، على أن توفير الصحة العامة والمياه النقية، لفقراء الدول النامية

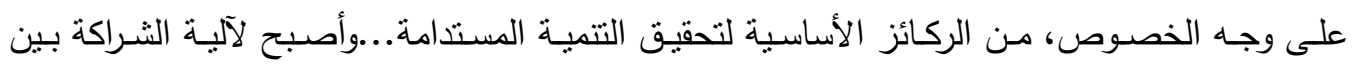

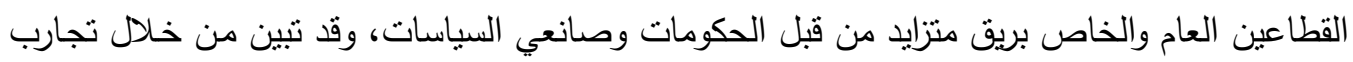

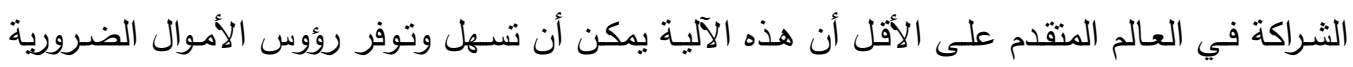

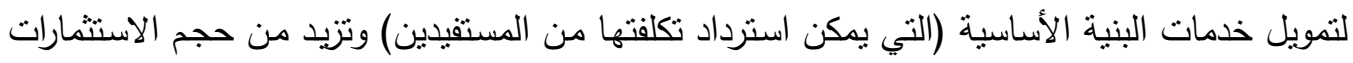

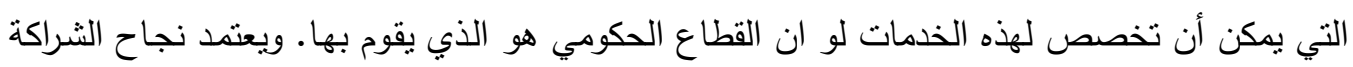

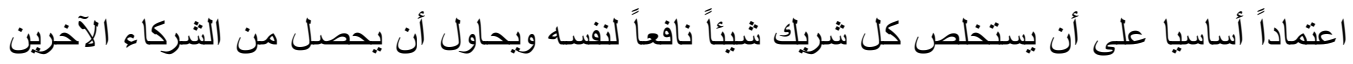

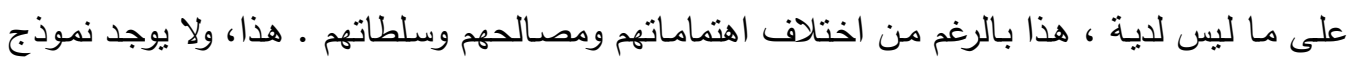

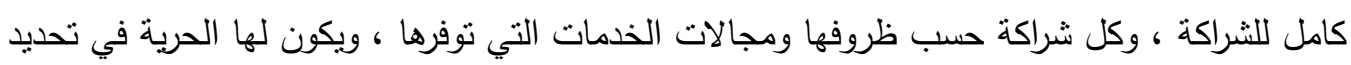

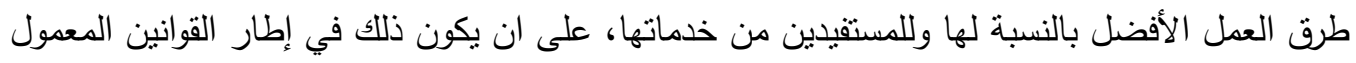

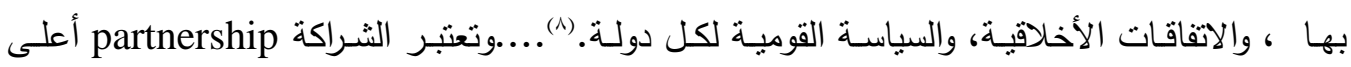

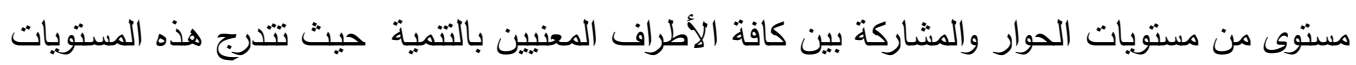

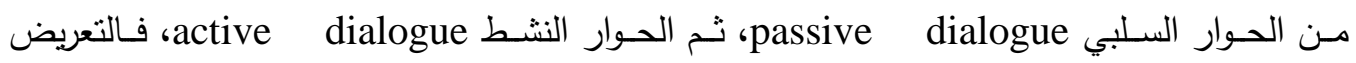




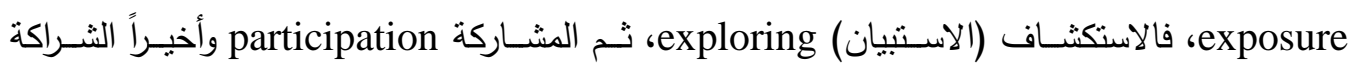

(9) partnership

\section{r-r الأطراف المشاركة بمشروعات الارتقاء .... وأدوارهم المتكاملة}

تؤكد المراجعة النظرية للعديد من الأبحاث والتجارب السابقة أن الثراكة الفاعلة لا تقتصر على الثراكة

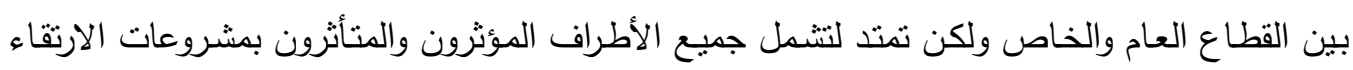
الحضري... حيث يؤكد البنك الدولي على أن مفهوم الثراكة بعني تكامل الأدوار بين شركاء التتمية،

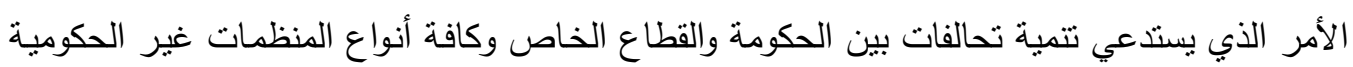

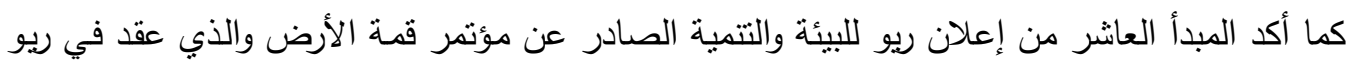

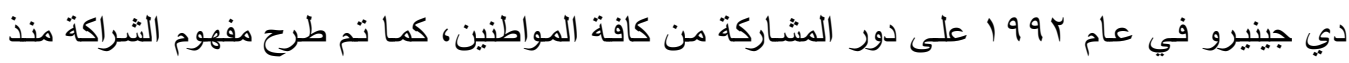

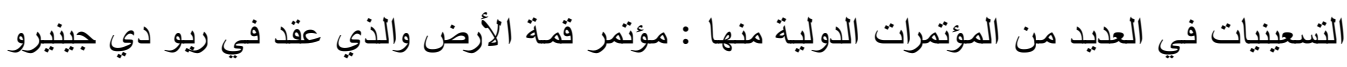

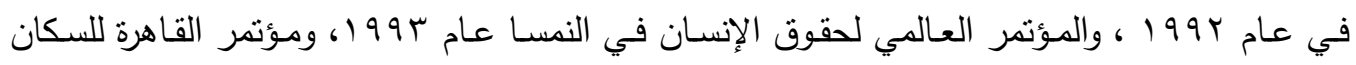

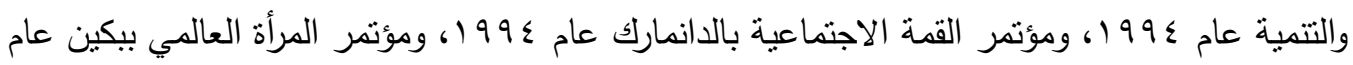

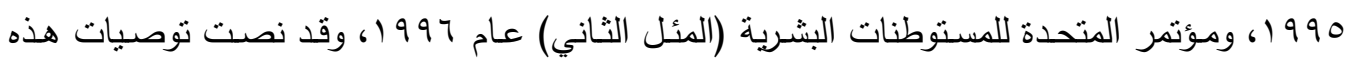

المؤتمرات جميعها على أهمية مشاركة جميع الأطراف في عملية النتمية بكافة أبعادها. (.)

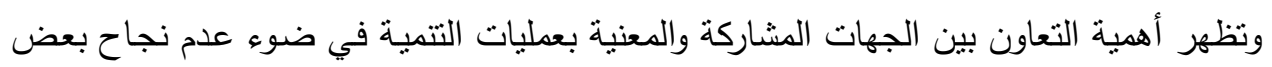

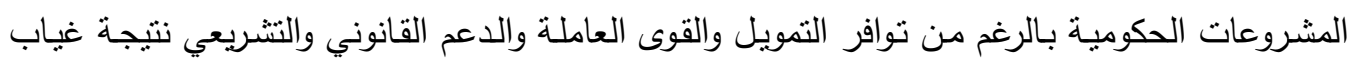

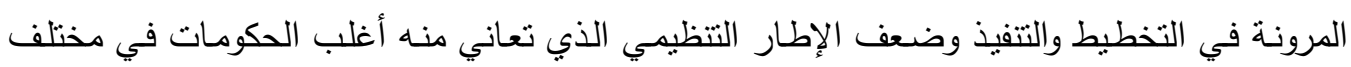
المستويات ، كذلك فإن المشروعات الصغيرة للمنظمات غير الحكومية والجمعيات الأهلية والتني غالباً ما

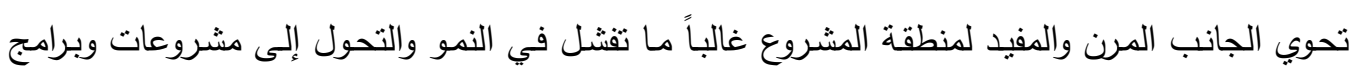

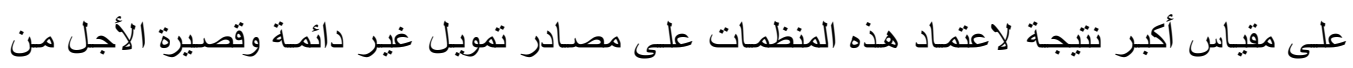

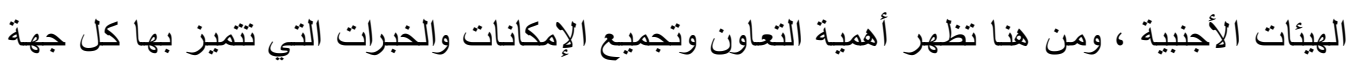
لإمكان الوصول إلى مدخل فاعل للتتمية. (11)

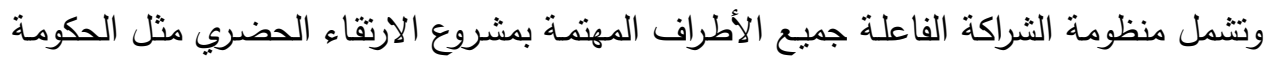
المركزية والمحليات والجهات المانحة (الدولية والمحلية) والمجتمعات المحلية والقيادات الثعبية والأهلية

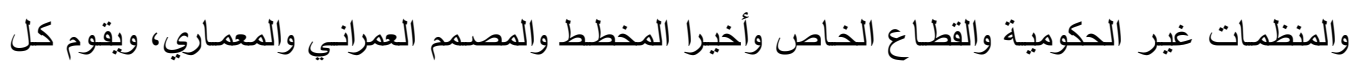
طرف بالمشاركة وفقاً لإمكاناته وقدراته والتي قد لا تتوافر في باقي أطراف المنظومـة، وبالتالي يمكن

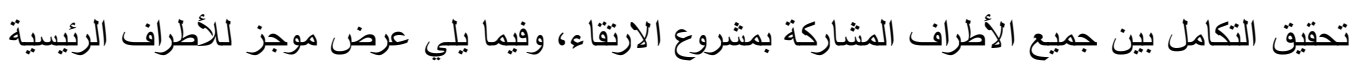
لمنظومة الثراكة الفاعلة ودور كل منها في تحقيق التتمية الحضرية المستدامة. 


\section{الحكومة المركزية :}

تختص الحكومة بالنواحي السياسية وتوجيه نوزيع الموارد مع إعداد أطر العمل المنظمة واللازمة لتنفيذ

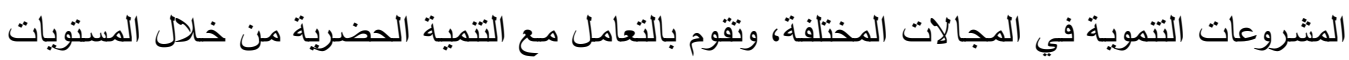
الحكومية الأخرى، وتمنلك الحكومة المركزية الممثلة في الوزارات ألمعينه بالتتمية ( مثل وزارة الإسكان

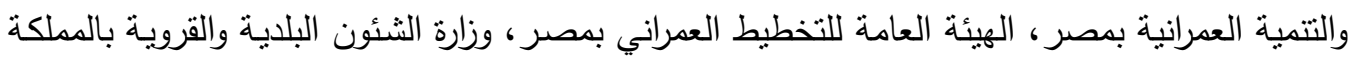

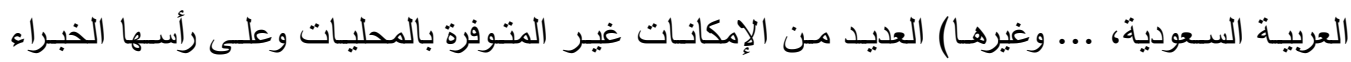

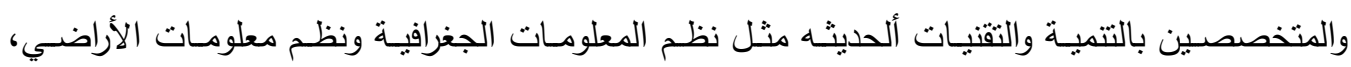
والمعرفة بالنظم الحديثة في التخطيط والتتمية.

\section{الحكومة المحلية:}

وهي تمثل المستوى الحكومي ذو الاتصـال المباشر بالسكان، وعادة مـا يكون عليها الالتزام الدستوري

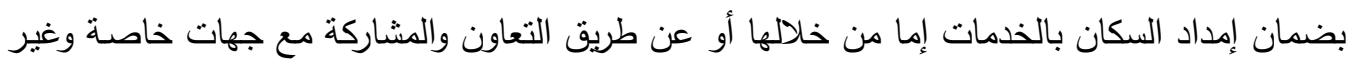

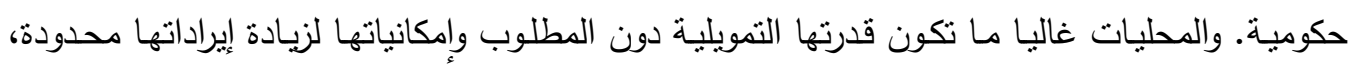

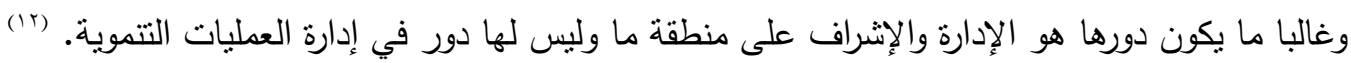

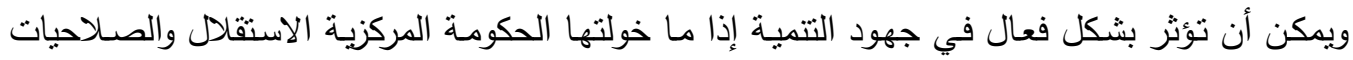

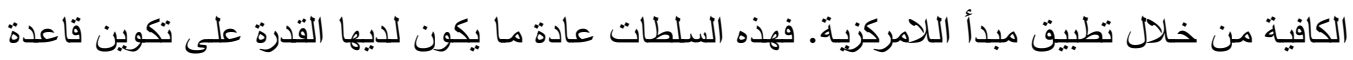

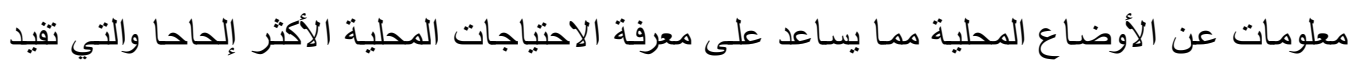
الفئات الأثد احتياجا. كما أن قيامها بالإثراف على تتفيذ البرامج الإنمائية يكون أكثر فعاليه وأقل تكلفه

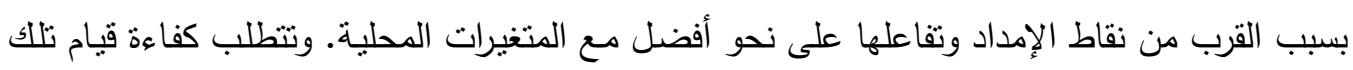
السلطات بدورها وجود آليات تضمن مستويات عاليهه من المشـاركة في تخطبط البرامج والسياسـات

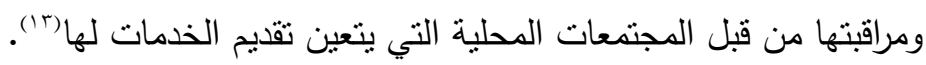

\section{المجتمعات المحلية :}

وهي يمكنها - إذا ما نوافرت الهياكل السياسية والمؤسسية المساعدة - القيام بدور فاعل في بناء رأس القاء المال الاجتماعي للمجتمعات العمرانية والذي يقصد به المؤسسات الاجتماعية التي تشمل علاقات الدات القرابة

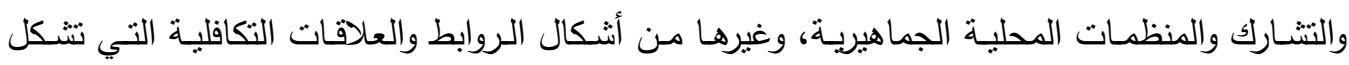

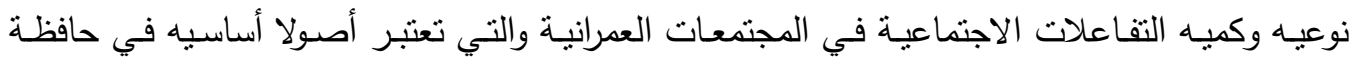

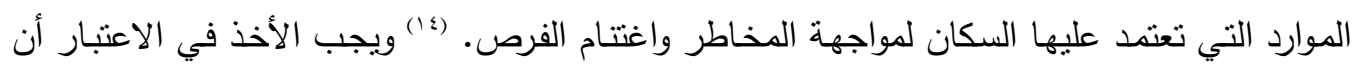

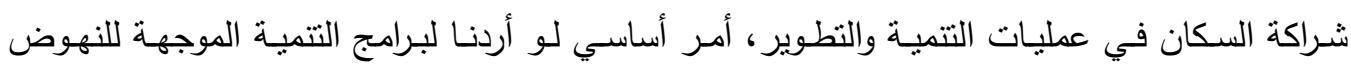

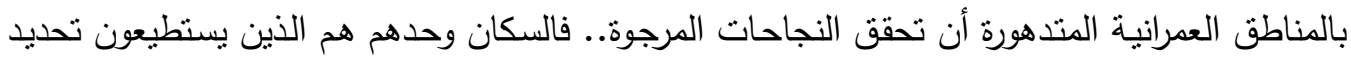

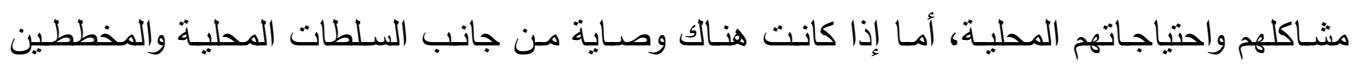


لفرض مشروعات بعينها - قد لا تمثل أولويـة لديهم - فإن مشـاركة السكان تكون محدودة. وتصبح

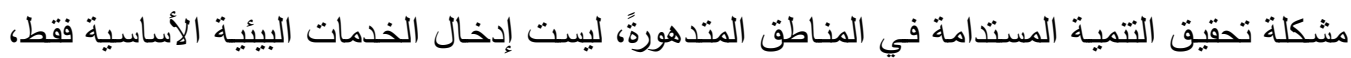
ولكنها في تتمية الموارد البشرية والمادية في المنطقة، وتزويد سكانها بالمهارات التي تمكنهم من العمل

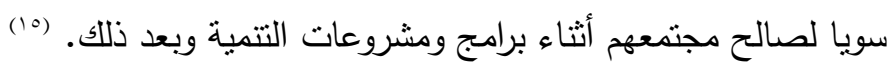

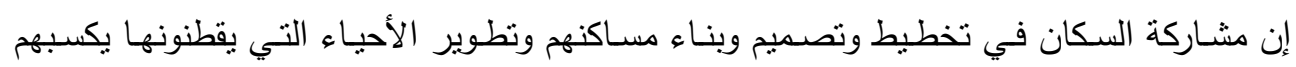

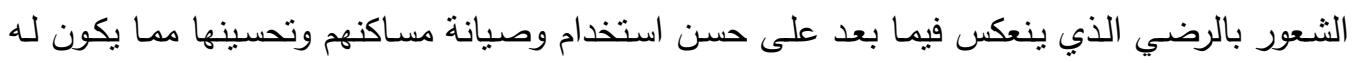

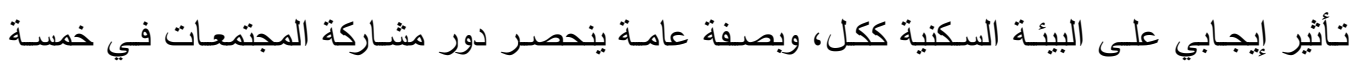

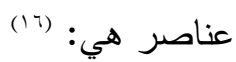

- المساهمة في تكاليف المشروع وذلك مـن خـلال مسـاهمة السكان بالمـال أو الأعمال أثنـاء

$$
\text { تتفيذ المشروع. }
$$

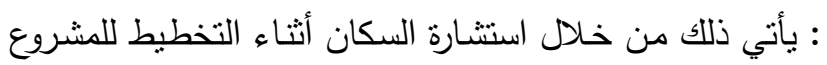

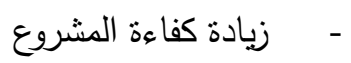

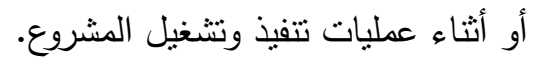
: ضـــان وصــول فائدة المشـروع إلـى المجموعـات السـكانية

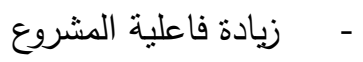
المختلفة.

: بكون هذا مـن خـلال ضـمان ربط المشـاركين فعليـا بعمليـة

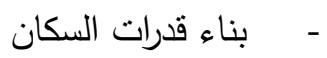
تخطيط وتتفيذ المشروع ( مثل تتكيل مجموعات بناء بالجهود الذاتية ) أو من خلال التدريب الرسمي وغير الرسمي والأنشطة

$$
\text { التي تزيد من درجة الوعي. }
$$

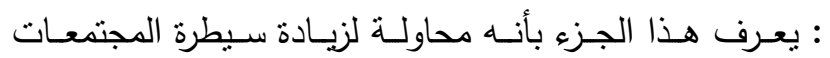
- - ميادة السلطة الممنوحة

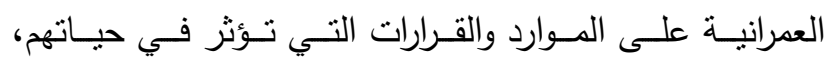

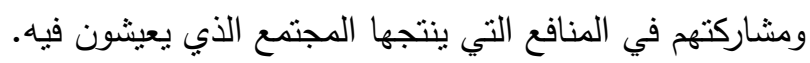
هذا بالإضـافة إلى الفائدة التي تعود على المحليات مثل تعرفهم على الاحتياجات والتفضيلات

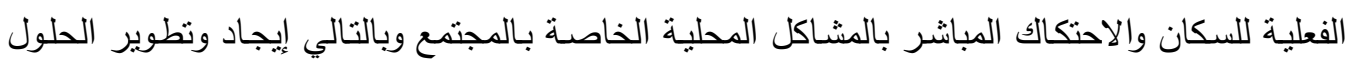
الملائمة. (iv)

\section{المنظمات غير الحكومية : المية}

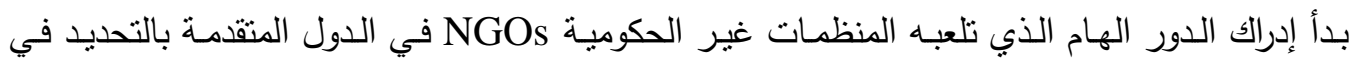

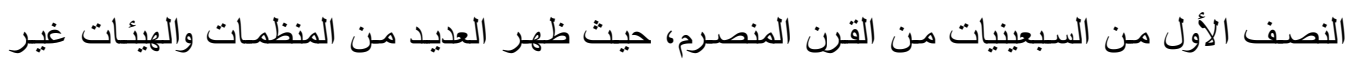
الحكومية التي ساهمت مع الحكومات والمجالس المحلية في تتفيذ العديد من مشروعات الارتقاء بالبيئة 
العمرانية للمناطق المتدهورة في مراكز المدن الكبرى في أوروبا كما حدث في ألمانيا وهولندا. ومع بداية الثمانينات بدأت هذه المنظمات في الظهور بالدول النامية خاصة بعد إدراك عدم قدرة الهيئات الحكومية على الاضطلاع بعبء تخطيط وتتفيذ كل مشروعات التتمية العمرانية للمجتمعات الفقيرة نظرا لعدم توافر

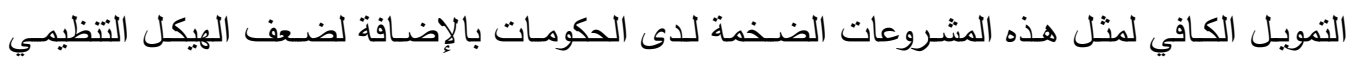

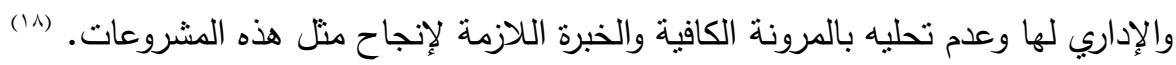

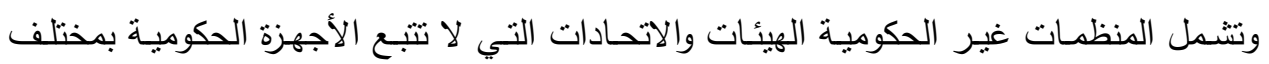
مستوياتها والتي أنشئت من أجل السعي لتحقيق أهداف تتموية على أساس لا يهدف إلا الربح، وتضم

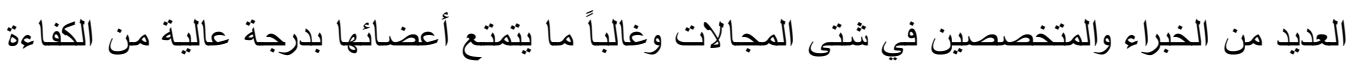
والالتزام. وتختلف فيما بينها اختلافا كبيرا في الحجم والثكل والتوجه والمذهب الفكري والموارد والفئات

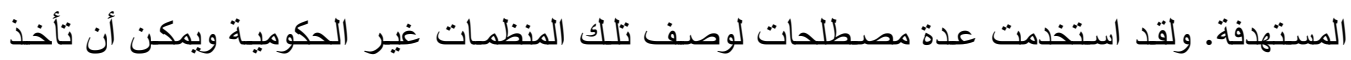

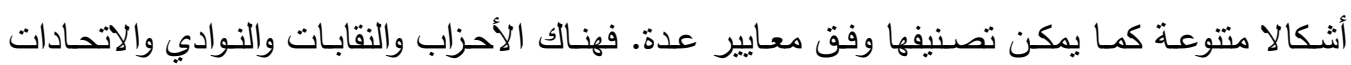
المهنية والطلابية والنسائية والجمعيات التطوعية المهتمة بالثئون الاجتماعية والتتموية.(19) ويعتبر الهدف

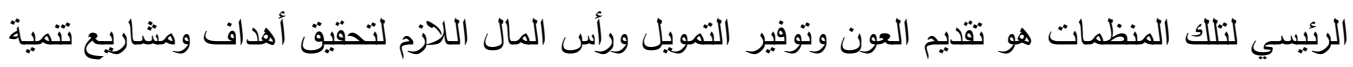

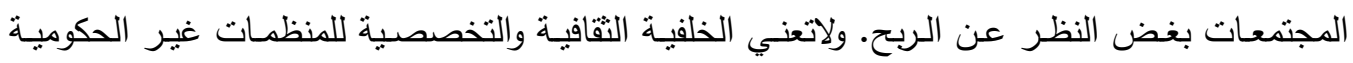

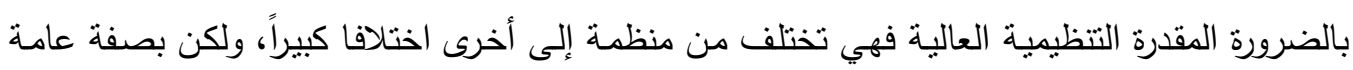

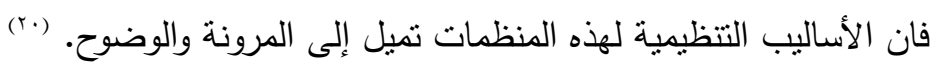
وتلعب المنظمـات غير الحكوميـة دوراً حاسماً في تحديد الاحتياجـات الحقيقة للمواطنين وتعبئة

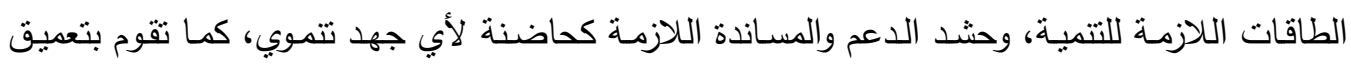

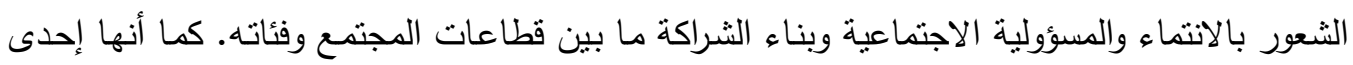

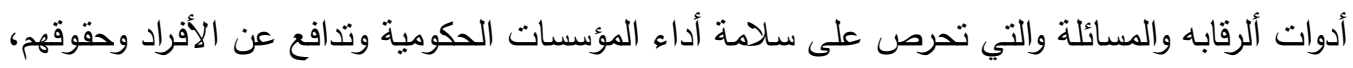

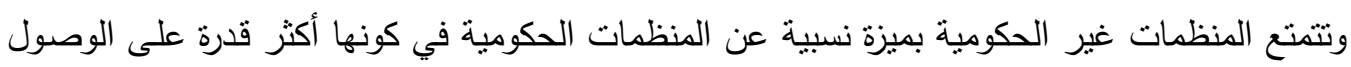

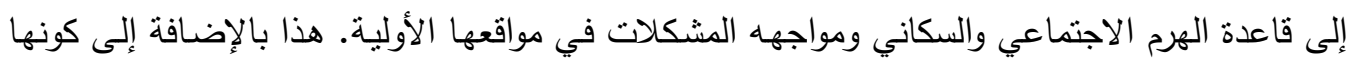

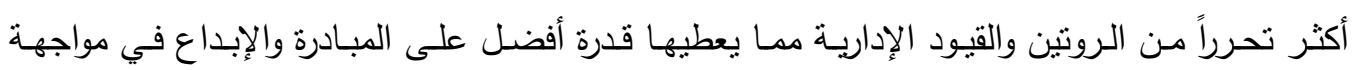
المشكلات. وهي تعد من القوى الفاعلة الرئيسية التي يمكنها المشاركة في تتفيذ سياسات وبرامج مكافحة

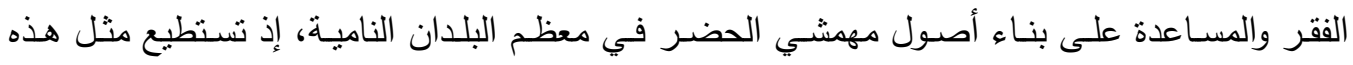

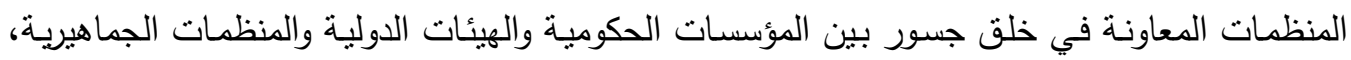

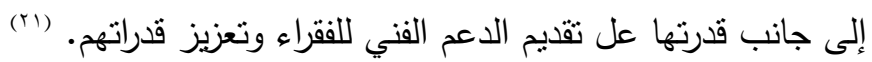




\section{الجمعيات الأهلية :}

وهـي نوعيـة مـن المنظمـات الرسمية أو غير الرسـية يـتم إنثـاؤها وإدارتها مـن قبـل النـاس استجابة

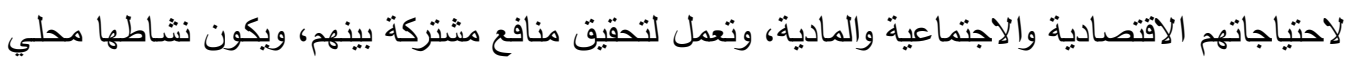
وقد تتشأ خصيصا لتزويدهم بالخدمات التي تتصهم أو تحسين الخدمات القائمة، وتكون مسؤلة مسؤولية

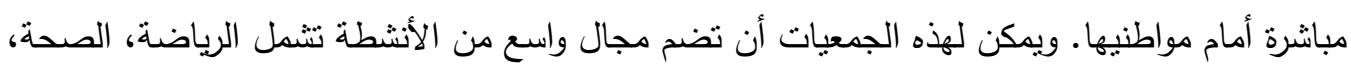

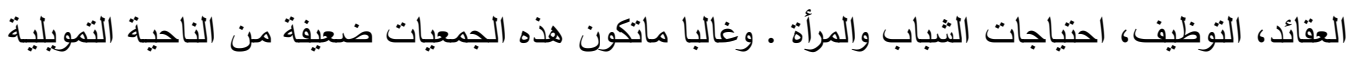

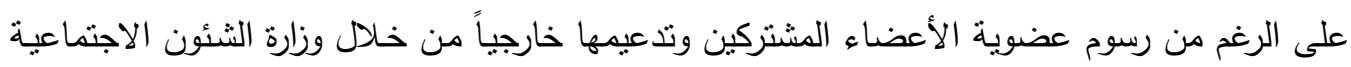
وغيرها من الجهات المانحـة، وكذللك غالباً مـا تفتقر إلى المهارات التخطيطية الفاعلـة خاصـة التتميـة المحلية.

\section{القيادات الثعية والأهلية :}

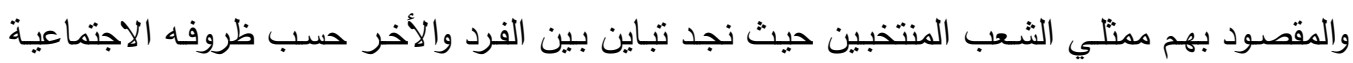
وتتشتئته النقافيـة وأسلوبه في العمل القيادي حيث بعتمد على شخصيته ومدى تأثيره على المواطنين

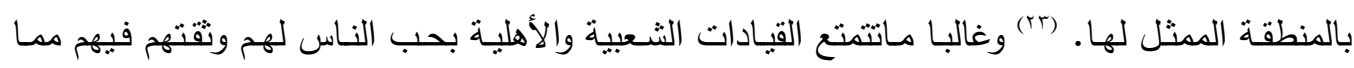
يجعل هـذه الفئَة حلقـة الوصـل الحقيقيـة بـين المسئولين عـن المشـروع (الحكومـة المحليـة، الحكومــة

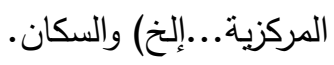

\section{القطاع الخاص:}

في ضوء الضغوط التي تعرضت لها اقتصاديات أغلب الدول ، فقد اضطرت إلي تطبيق برامج تصحيح

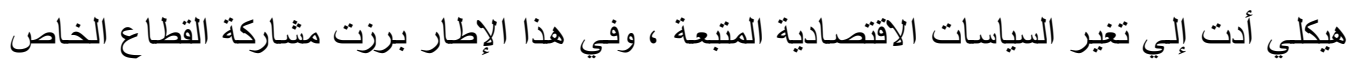

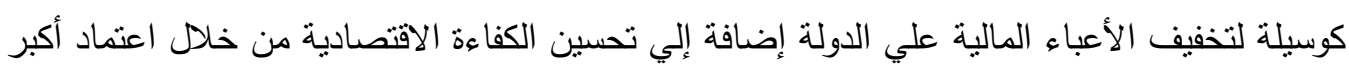

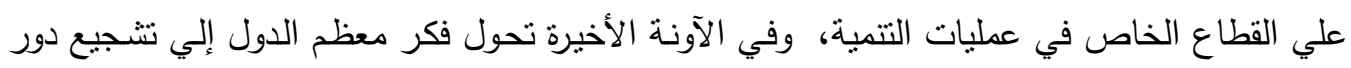

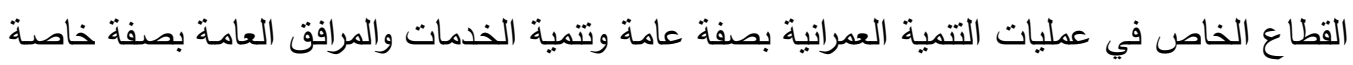

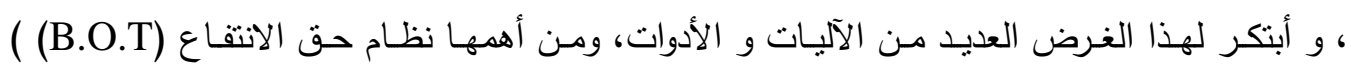
Build/Operate/Transfer

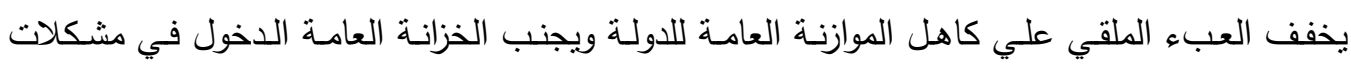

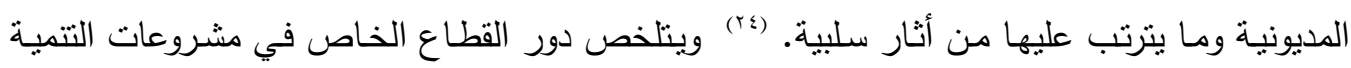
الحضرية في التالي: (10) أولا- الدور الاقتصـادي : أصبح الدور الاقتصادي للقطاع الخاص هام جداً في التتميـة الاقتصـادية

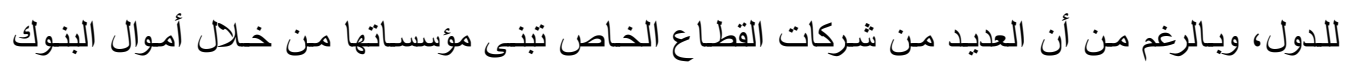
ومشاركة الثركات الأجنبية إلا أن زيادة الاستثمار والإنتاج له من التأثنير المباثشر على تحقيق معدلات 
ادخار متزايدة من خلال توسيع قاعدة الملكية وربط هذه المدخرات مع قواعد الإنتاج عن طريق سوق

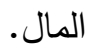

ثنانياـا الدور الاجتمـاعي :يقصد بالدور الاجتمـاعي مـا يمكن أن يقدمهـ رجال الأعمال من خدمات

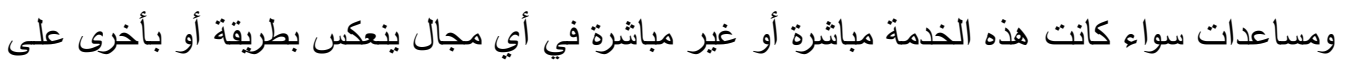
تحسين أو مساعدة أفراد المجتمع، ويمكن أن يحدد الدور الاجتماعي لرجال الأعمال من خلال: 口 ت توفير فرص عمل جديدة للمواطنين للتظلب على مشكلة البطالة.

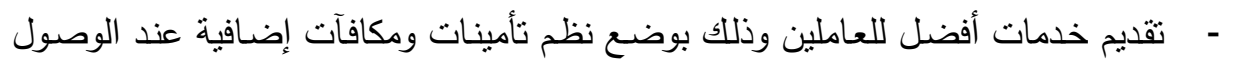
إلى سن المعاش بهدف استقرار العمالة وعدم تركها للعمل وتقرغها للإنتاج.

\section{المخطط والمصمم العمراني Urban Planner/Designer}

شهـ التخطيط الحضـري تطوراً هـائلاً في مفاهيمهـه وممارسـاته وتطور دور المخطط ليواكب تطورات

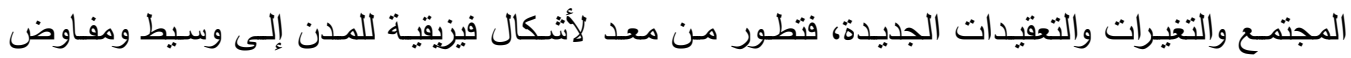
Habitat II ومسهل لعملية اتخاذ القرار وإنجاز المخططات. وقد نادت العديد من المؤتمرات الدولية مثل فئل

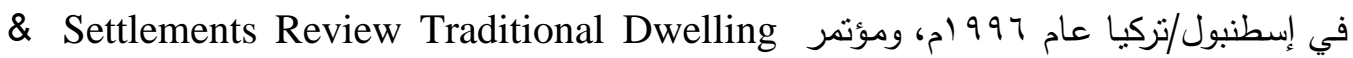
والذي عقد بالقـاهرة في ديسمبر 991 ام بدور جديد للمخطط العمراني في الألفيـة الميلاديـة الثالثة، وأوصت بأن يتحول دور المخطط ليكون وسيط mediator ومرشد advocate لكافة عناصر المجتمع.

فمن الإثكاليات التي تواجه مشروعات التتمية بصفة عامة ومشروعات التتمية الحضرية بصفة

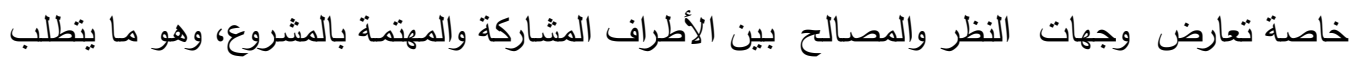
وجود وسيط facilitator يساعد على استمرارية الحوار بين الأقطاب المختلفة وتمكين المجتمعات ومنحهم السلطة empowerment والمساهمة في حل التعارضات التي قد نظهر خلال إعداد مشروع التتمية ـ من ناحية أخرى في التجمعات العمرانية التي نتشنمل على فئات متعددة تأخذ الطبقة الغنية والمتوسطة high \& middle classes people الفرصة للتعبير عن أرائهر من

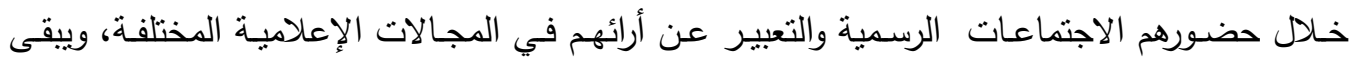

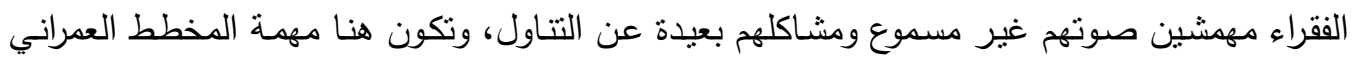

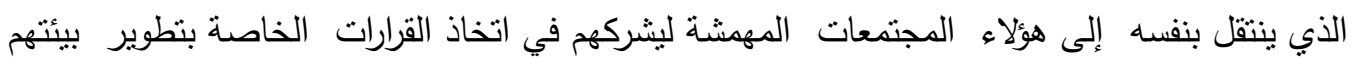

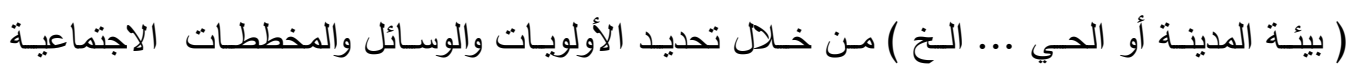
والاقتصادية قريبة وبعيدة المدى. (广^). 
شكل (1) : المخطط العمراني كوسيط بين أطراف المشاركة المجتمعية (Yv)

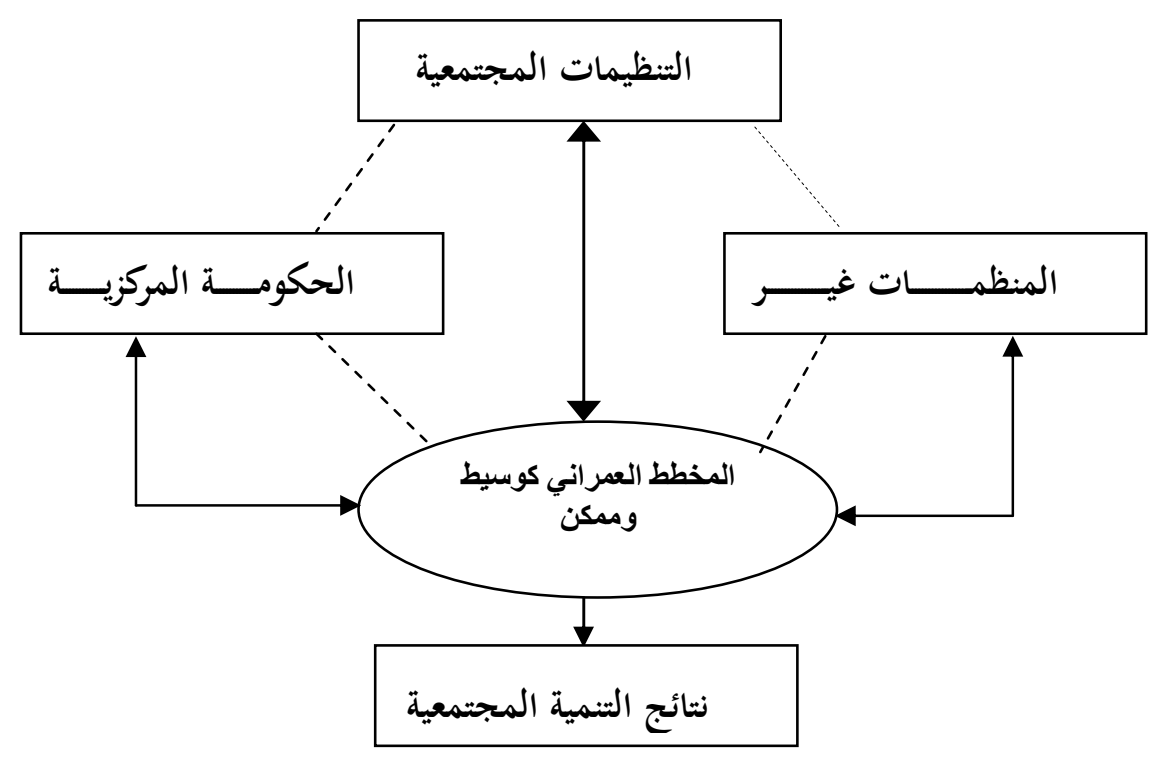

\section{الجهات المانحة المحلية والدولية :}

وتتــمل الجهات الممولــة لمشـروعات التتميـة سـواء كانـت محليـة مثل الصـندوق الاجتمـاعي للتنميـة (بمصر)، أو دولية مثل برنامج الأمم المتحدة الإنمائي UNDP، حيث يكون لهذه الجهات اشتراطات

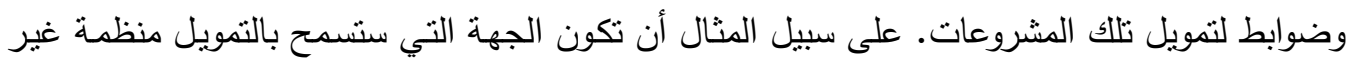
حكومية أو جمعية أهلية أي أن وزارة الثئون الاجتماعية تقوم بدور الرقيب عليها وذلك ضمانا لأموالهون.

\section{ع - التجارب السابقة والاروس المستفادة}

بدايـة من السبعينيات من القرن المبلادي المنصرم بدأت الحكومة المصرية في تبني مدخل الارتقاء الحضري كبديل واقعي واقتصادي لنطوير المناطق العمرانية المتدهورة داخل وحول المدن، وقد اتسمت لهن التجارب الأولى بالمشاركة المحدودة للأهـالي في عمليات التطوير بمراحلها المختلفة، ولكن سرعان العهان

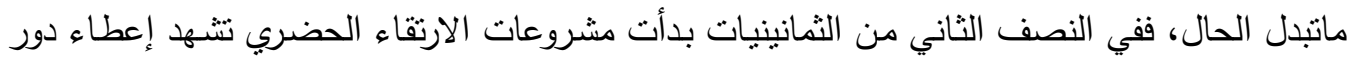

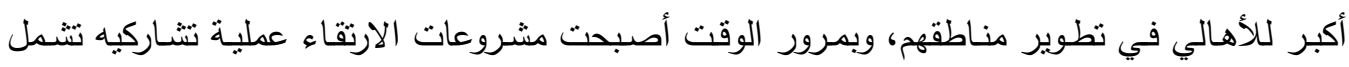

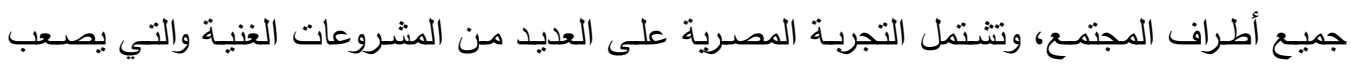
تتاولها جميعاً بالدراسة والتحليل، منل مشروع المواقع والخدمات بحي السلام بمدينة الإسماعيلية، ومشروع

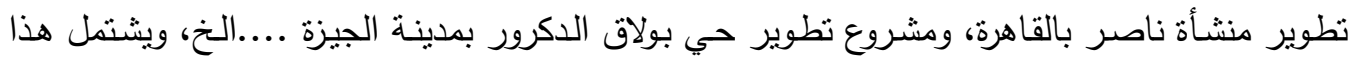


الجزء من البحث على عرض وتحليل لثناث تجارب للخروج ببعض المؤثرات والدروس المستفادة لتحديد شركاء التتميـة وأدوارهم بمشروعات الارتقاء الحضـري، وقد تم اختيار هذه التجارب لعدد من الأسباب

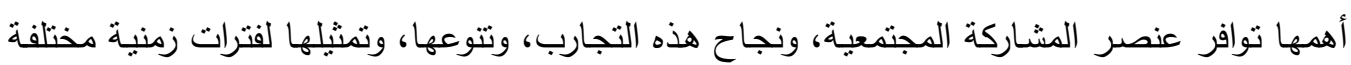

\section{ع - 1 مشروع الارتقاء الحضري بمنطقة الناصرية بمدينة أسوان :}

يعتبر مشروع الناصرية أحد المشروعات الرائدة في مجال الارتقاء بمناطق الإسكان غير الرسمي في مصر ، وقد تم المشروع بالمساعدة الفنية والمالية من الوكالة الألمانية للتعاون الفني (GTZ) ، منذ بدء المشروع في نهايات العقد الثامن من القرن المنصرم وذلك بالتعاون مـع الهيئة العامـة للتخطبط العمراني بمصر ومحافظة أسوان • وتعتبر منطقة الناصرية أحد أحياء مدينة أسوان وتقع على بعد نحو بكم شرق مدينة أسوان، ويبلغ عدد سكانها نحو . . . .0 نسمة (ربع سكان مدينة أسوان) معظمهم من المهاجرين النوبيين الذين نزحوا للمنطقة في نهاية العقد الخامس من القرن المنصرم للعمل في تعلية خزان أسوان وبناء السد العالي • ويتميز التكوين المجتمعي للمنطقة بالقبلية، حيث يستقر كل مجموعة من السكان (مثل القبيلة) في شارع أو منطقة واحدة .(r.)

وقد استهدف مشروع الارتقاء تحسين الجوانب العمرانية Physical Improvement والنواحي الاجتماعيـة الاقتصـادية للسكان. وقد تم تتفيذ المشـروع بمشـاركة فريق عمل مكون من مجموعـة مـن الخبراء والمتخصصين وممتلين عن أفراد المجتمع. وقد تم إنجاز وتتفيذ تمديد البنية الأساسية وتحسين القائم منها من شبكة المياه والصرف الصـحي من خلال السكان تحت إثـراف وتوجيهات فريق العمل بالمشروع، وقد أدت هذه التجربـة إلى تعزيز الروابط والتتظيمات المجتمعيـة وتسهيل عمليات المشاركة بالمراحل التالية بالمشروع. ومن خلال هذا المشروع تم تأسيس عدد من جمعيات تتمية المجتمع (جمعية واحدة لكل منطقة

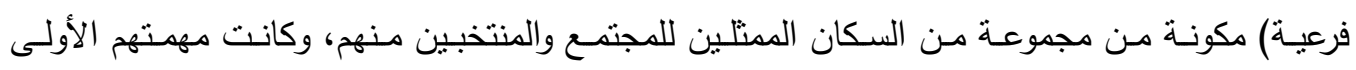
تتحصر في نقل وجهات نظر السكان واحتياجاتهم إلى فريق المتخصصين بالمشروع. ومن خلال هذا المجتمع المنظم تم إنجاز العديد من التحسينات مثل عمل وتتفيذ نظام للتخلص من المخلفات الصلبة، تحسين وتوسعة المدارس، طرح برامج وأنشطة للشباب، وتأسيس برامج اجتماعية وأنشطة تدريبية لنحو

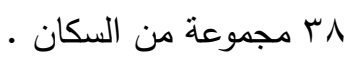

وقد اشتمل مشروع الارتقاء بالناصرية على تفاعلات تشـاركيه في مختلف مراحل المشروع ففي

بدايـة المشـروع تم عمل استقصـاء من خـلال اجتماعـات غير رسمية للتعرف على احتياجـات السكان وأولوياتهم ، وقد أدى إجماع الأهالي على الاحتياج للبنية الأساسية إلى دعم تتفيذ المشروعات والمشاركة فيها، وقد شجع السكان في ذلك رغبة محافظة أسوان في قيام السكان بتتفيذ العمل . 
ويعكس مشروع الارتقاء بالناصرية تجربة تؤكد على ضرورة احترام التنظيمات المجتمعية القائمة ودعمها للحصول على المشاركة الفاعلة، فبعد الانتهاء من تتفيذ مشروعات البنية الأساسية تبنى القائمون

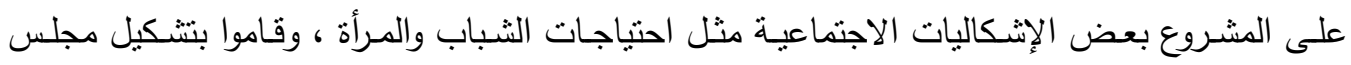
مجتمعي Community Council مكون من ممثلين منتخبين من المجتمعات الفرعية بالمنطقة، ولكن الكني

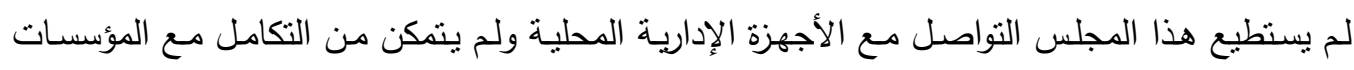

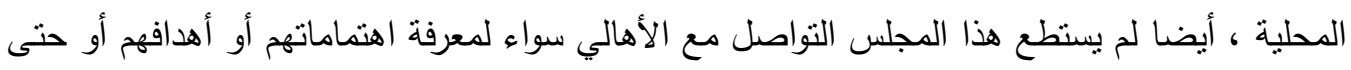

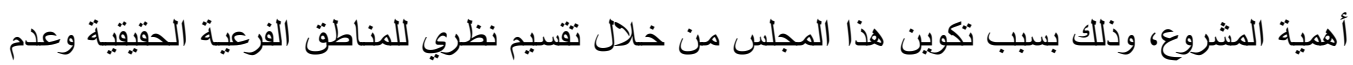

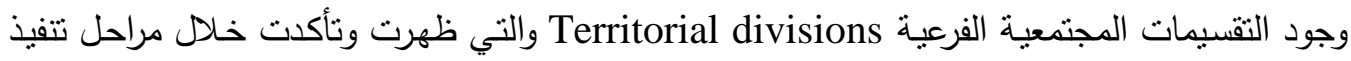
البنية الأساسية فقد جاء هذا التقسيم لأسباب فنبة بحته بغرض أعمال الحصر وجمع البيانات ولم يتت

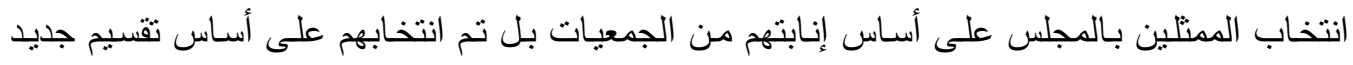

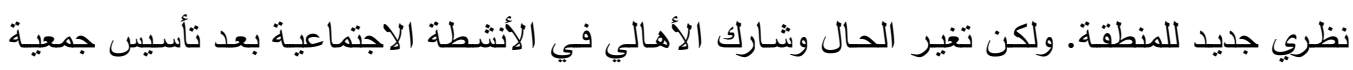

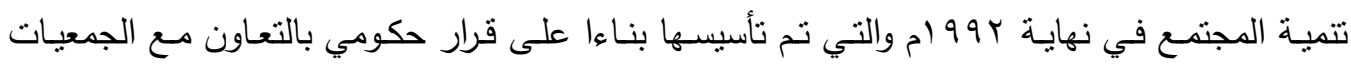

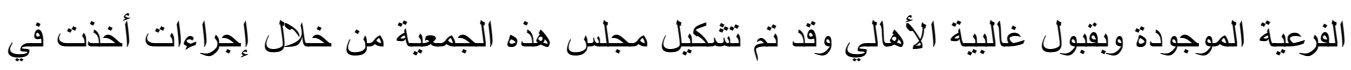

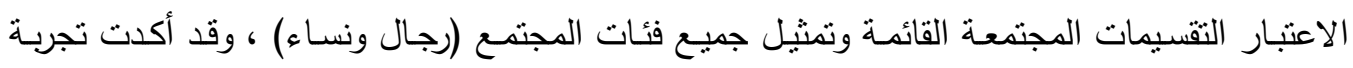

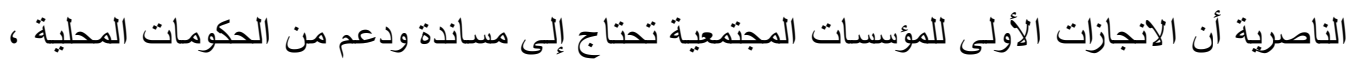

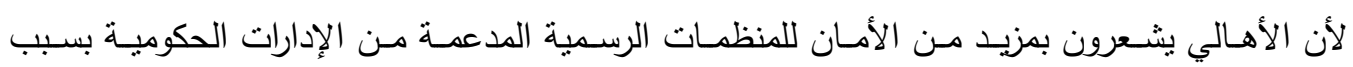

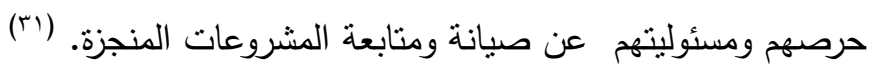

\section{ع - r مشروع الارتقاء بعزبة وعرب الوالدة بمنطقة حلوان بالقاهرة :}

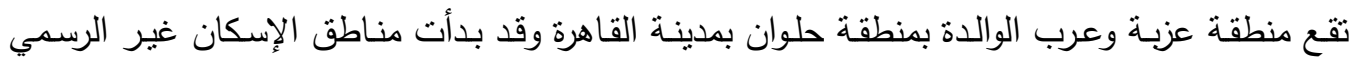

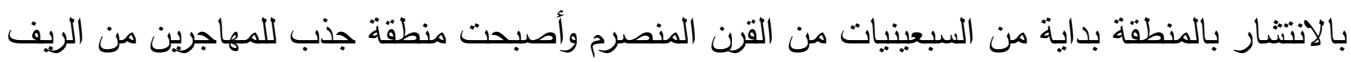

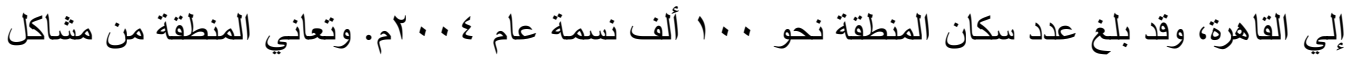

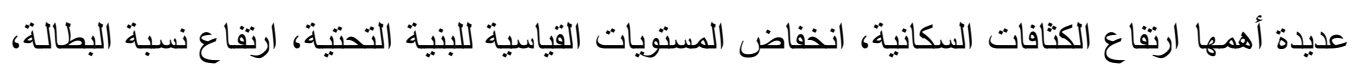

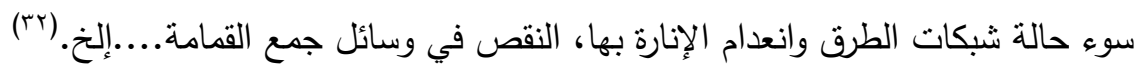

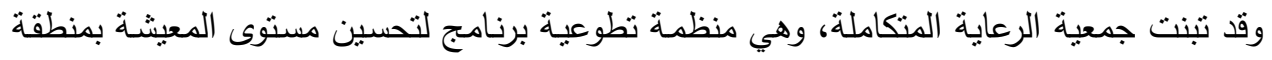

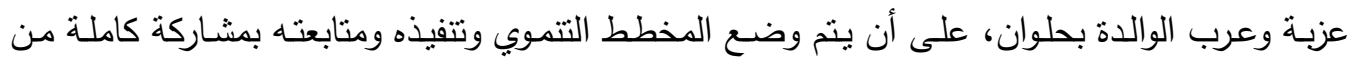

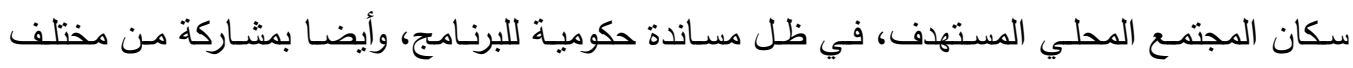

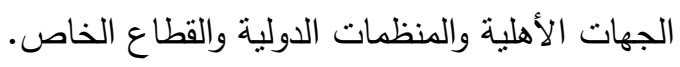
وتمثنل الهدف العـام للمشـروع في تحسين مستوى المعيثـة بالمشـاركة في عزبـة وعرب الوالدة،

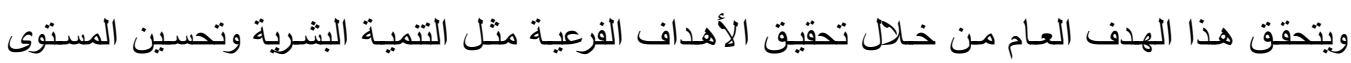


الصحي والتعليمي للسكان والارتقاء بمستوى البنية الأساسية بالمنطقة وتحديد الثركاء المحتملون في كل نشاط تتموي مطلوب.

وتم تحقيق أهداف البرنامج المقترح من خلال دراسة المجتمع وتهيئته وتحديد الاحتياجات من كافة الفئات والتتسيق مع الجهات الحكومية والأهلية الداعمة وتتفيذ المشروع التتموي بالمشاركة. وقـد بـدأ المشـروع بمبـادرة وتمويل مشـترك بين الحكومـة المصـرية ممنلـة في محافظــة القـاهرة

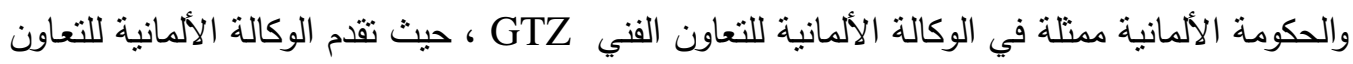

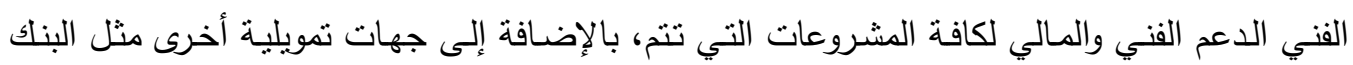
الأهلي، الصندوق الاجتماعي للتتمية، وجهات التمويل الدولية.

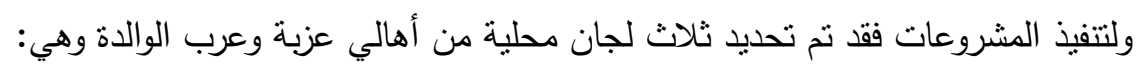

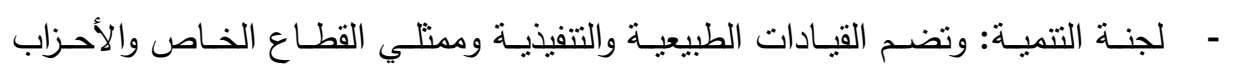

$$
\text { والجمعيات الأهلية، }
$$

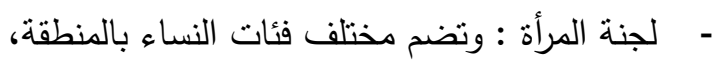

$$
\text { 口 ل لجنة الثباب : وتضم الثباب من الجنسين }
$$

وتتثكل كل لجنـة عمل من مسئول من الوزارة التابع لها المشروع، المسئول التتفيذي بالمحافظة

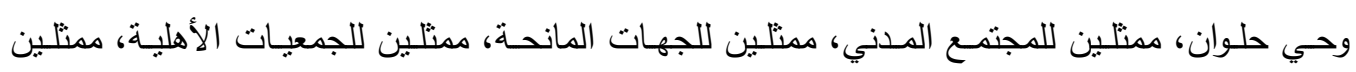

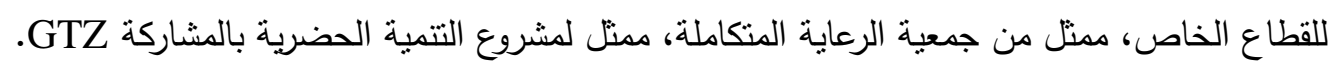
وتقوم كل لجنة بتحديد المشروعات الواقعة في مجال عملها ودراسة طرق تتفيذها، وتحديد ميزانية

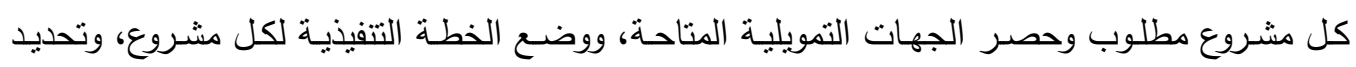
الترتيات الفنية والمالية والإدارية التي تمكن ممنلي المجتمع المدني من المشاركة في تشغيل وصيانة كل

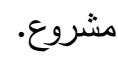

هذا ويعكس برنامج تطوير عزبة وعرب الوالدة بحلوان مشاركة العديد من الجهات على النحو النالي:

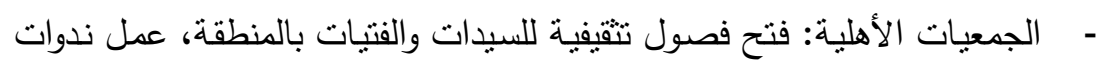

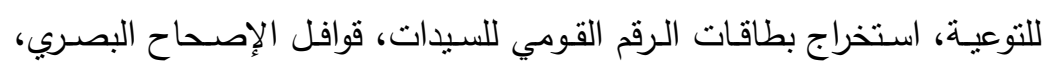

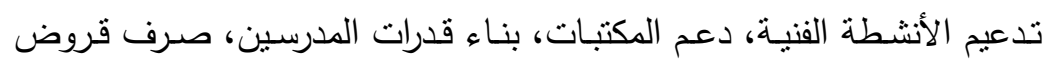

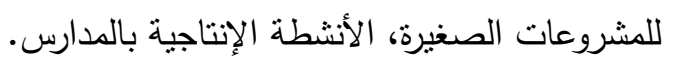

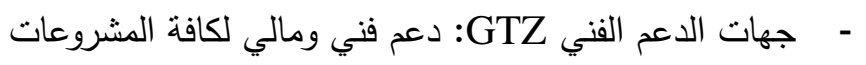
口 المجلس القومي للمرأة : استخراج بطاقات الرقم القومي للسيدات بالمنطقة

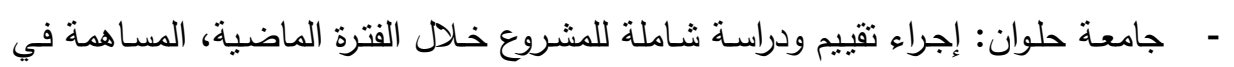
وضع المخطط العمراني التقصيلي للمنطقة 
] القطاع الخاص: مساعدات اجتماعية، دعم القوافل الطبية، المساعدة في إنثاء المركز

الطبي، توزيع أغذية جافة على الأسر الفقبرة، المساهمة في توفير الزى المدرسي للطلبة اعلية

$$
\text { الفقراء (0.70 طالب). }
$$

_ [ الجهات التمويلية : البنك الأهلي (دعم القوافل الطبية والمركز الطبي).

$$
\text { جدول رقم (ץ) : الأطراف المشاركة وأدوارهم بمراحل العمل }
$$

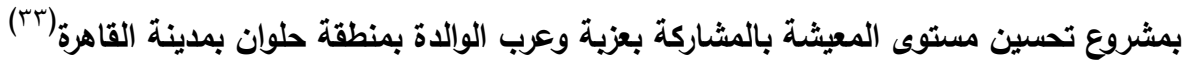

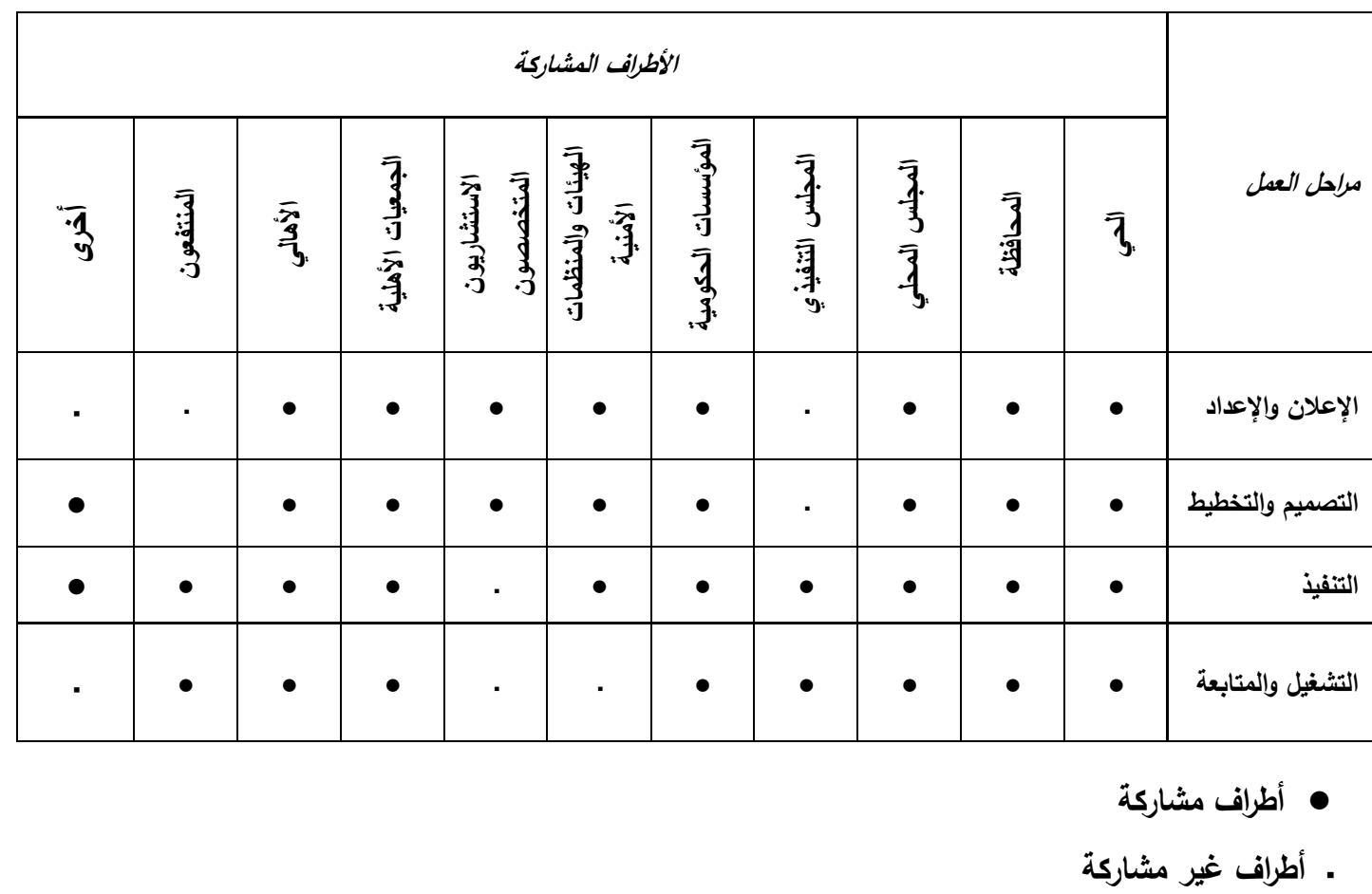

ع - مش مشروع التنمية الثاملة لمدينة قنا

تقع مدينة "قنا" على بعد نحو .7 كيلو متراً جنوب مدينة القاهرة ويبلغ عدد سكانها نحو . نسمة (عام 999 (1). وقد قامت محافظة قنا بنهج سياسات وآليات تتفيذ برنامج التتمية الثاملة للمدن بالمحافظة في إطار توجهات الدولة، وقد اتبعت سياسـات واضحة وصريحة ومحددة قوامها التعاون

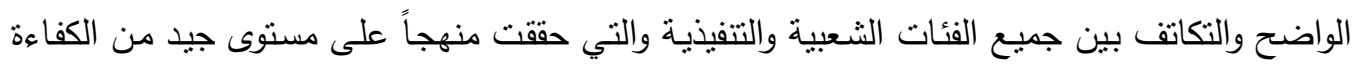

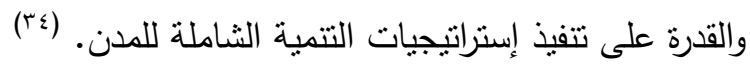
هذا ويمكن إيجاز آليات الثراكة المتبعة بالمشروع فيما يلي: (ro) 
تفعيل الجهاز الإداري والتنفيذي بمدن المحافظة : - الجهاز الإداري بالمحافظة : برئاسة المحافظ، والذي أسس نظام إدارة وتقعيل النوجهات

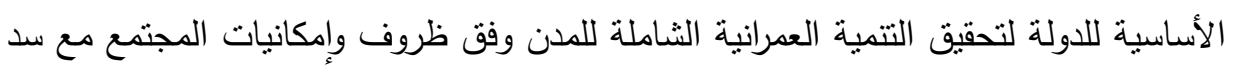

$$
\text { الاحتياجات الضرورية للسكان بالمدن. }
$$

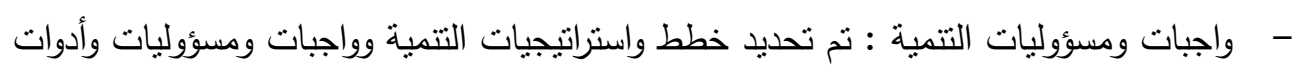

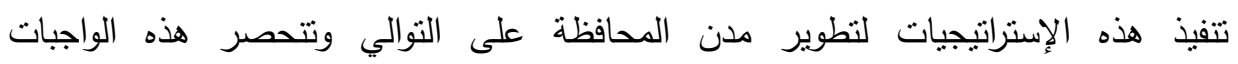

$$
\text { والمسؤوليات فيما يلي: لفئن الإنئيات }
$$

• مباشرة تتفيذ الواجبات على أرض الواقع من محافظ الإقليم.

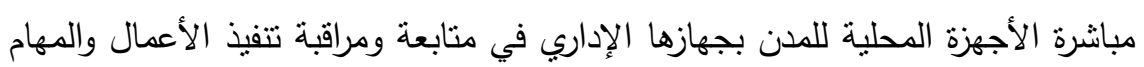

$$
\text { بصفة أساسية وفق البرنامج الزمني المحدد. }
$$

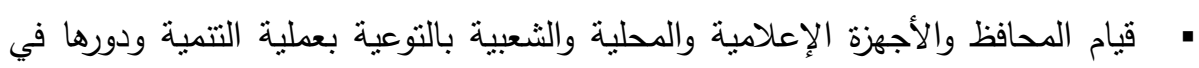

تحقيق مستوى معيشي مناسب للسكان، والارتفاع بالمستوى الحضاري للمدن ومجتمع بالئه

$$
\text { السكان. }
$$

• ث السكان على الحفاظ على النظافة العامة للمدينة وإلقاء المخلفات في أماكنها

$$
\text { المحددة وعدم إبقاء أية مخلفات على الطرق أو الحدائق. }
$$

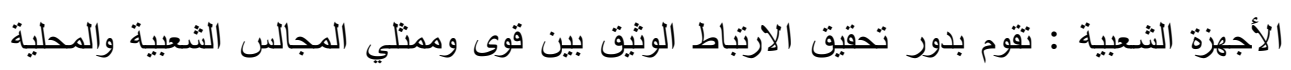

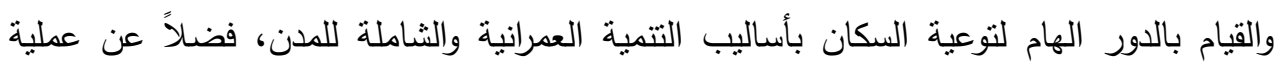

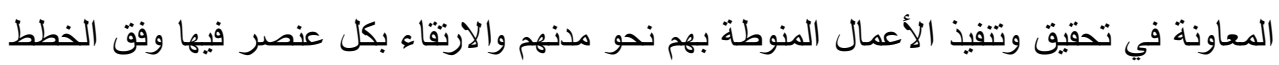
التتموية الثاملة التي تعدها الأجهزة المحلية المسئولة. قطاع المقاولات: تم حصر وتجميع قطاع مقاولي القطاع العام والخاص وجمعيات رجال الأعمال وتحديد دور كل منها نحو عمليات تتفيذ الأعمال التتموية بالمدن وتكليف كل منها بالتنفيذ والالتزام

$$
\text { بالمواصفات الفنية. }
$$

قطاع الثباب: نم حصر الثباب وتحديد تخصصاتهم وتحديد الأعمال التي يمكنه أداؤها وتثغيلهم وخصوصاً العمالة من فئات الثباب العاطل والعمل على تحسين مستوى معيشتهم. تمويل مشروع التتمية : تم تحقيق التفاعل بين القوى الثعبية في جمع التمويل اللازم لعمليات

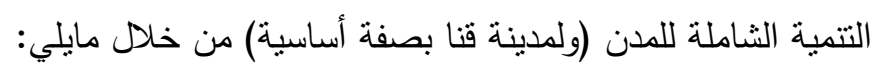
- - جمع التبرعات من المحلات التجارية والخدمات الخاصة بالمدينة مقابل أعمال التحسينات والتطوير للطرق والبنية الأساسية. 
- بالإقناع تم فرض رسوم تتمية ميسرة وشاملة لجميع السكان على جميع الطلبات المقدمة

$$
\text { إلى الهيئات الحكومية. }
$$

- - فرض رسوم محددة وميسرة على فواتير التليفونات.

- فرض رسوم محددة وميسرة على فواتير الكهباء والإنارة تتاسب حالات الخدمات

$$
\text { والمحلات والثركات وكذلك الإسكان بالمدينة. }
$$

تعاون الأجهزة العلمية: تم التعاون بين أساتذة الجامعات والفنانين التشكيليين لعمليات التجميل التي والتيني

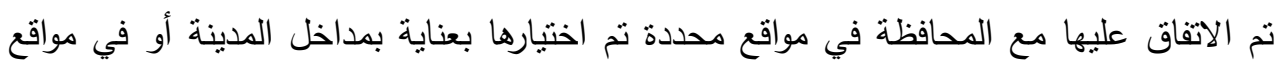
المزارات الدينية والسياحية.

تتشيط أعمال إدارة الحدائق والبساتين بالدحافظة : تم تفعيل قوة العمل بتثغيل الثباب في مجال

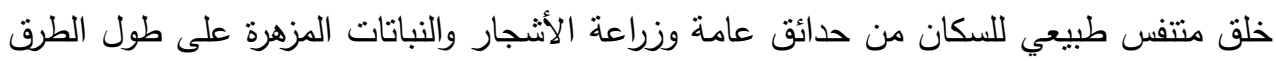

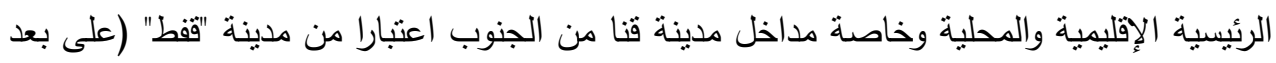

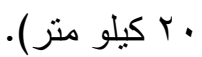

\section{الانعكاسات على البيئة الحضرية :}

$$
\text { - - - إيجاد بيئة عمرانية حضرية جيدة. }
$$

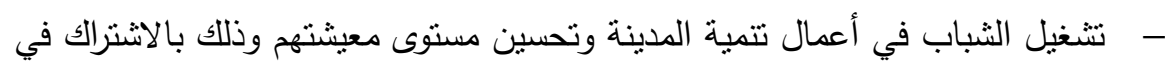
أعمال المقاولات المختلفة.

-

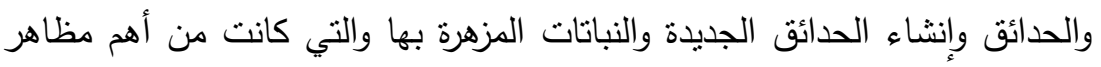
الجمال في أرجاء المدينة ومداخلها وفراغاتها وميادينها.

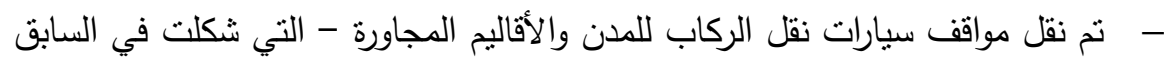

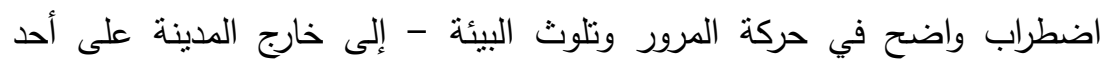

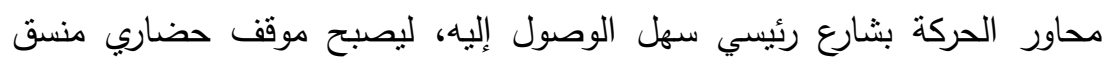
لحركة الدخول والخروج وبمظلات للحماية من أثعة الثمس وحرارتها العالية. - - تعظيم الاستفادة من الفراغات والميادين داخل المدينة بزراعة مساحات منها بالأثجار وعمل نوافير المياه والرموز الجمالية والنحتية والجداريات مع نتظيم حركة المرور الآلي والمشاة بها. - والدهانات للمباني مع إضافة بعض الكرانيش بألوان مناسبة، والذي نم تلفيذه بتوجيهات وإقناع السكان من القوى الشعبية والتتفيذية. 
- - إضافة صورة حضارية مميزة لمداخل المدينة من جهة مدينة الأقصر السياحية (المدخل القلبي للمدينة) وكذلك من جهة المدخل الغربي البحري للمدينة وتحقيق وإظهار الاهتمام الواضتح بأعمال التجميل لاستقبال السياح وزوار المدينة. - - حقت عملية التتمية الثاملة بمدينة قنا البداية الصحيحة التي أعطت صورة حقيقية وجادة جعلتها مثالاً يحتذى به في باقي مدن المحافظة حيث بدأ التتفيذ الفعلي لخطة تحسين البيئة العمرانية لبعض مدن المحافظة وهي مدن نجع حمادى ومدينة قفط التي تم تحسين الطريق الإقليمي من مدينة قنا إليها وزراعة الأشجار والنباتات المزهرة على جوانبه بطول حوالي عشرين كيلو منراً تقريباً. ه - نتائج البحث

\section{موجز الأطراف المشاركة وأدوارهم المتكاملة}

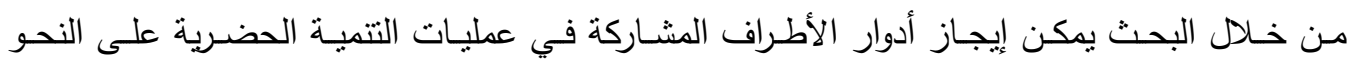

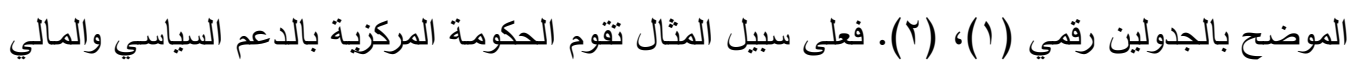

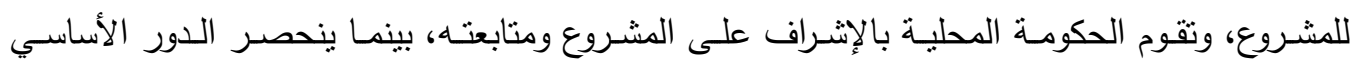

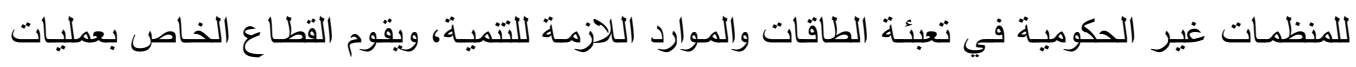

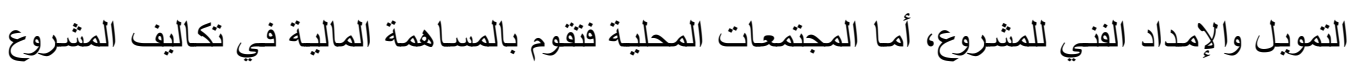

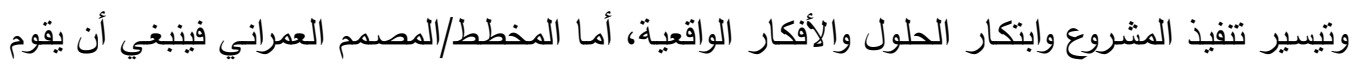

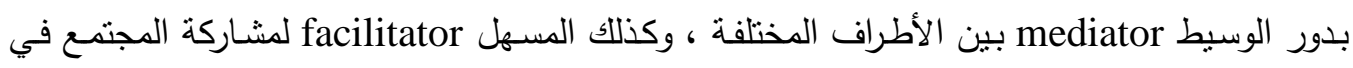
صناعة القرارات . 
جدول رقم (1) : شركاء التنمية وأدوارهم في مشروعات الارتقاء الحضري

\begin{tabular}{|c|c|}
\hline الأدوار / المهام الرئيسية & الجهات / الأطراف المشاركة \\
\hline 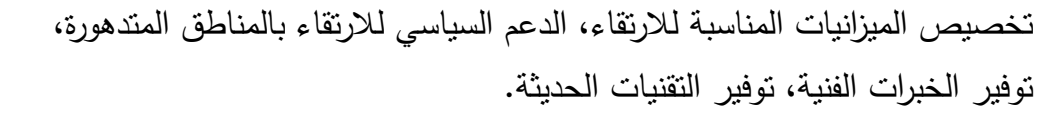 & الحكومة المركزية \\
\hline تحديد الإحتياجات المحلية الملحة. مشروع الارتقاء، نوفير قاعدة المعلومات عن الأوضاع المحلية، & الحكومة المحلية \\
\hline 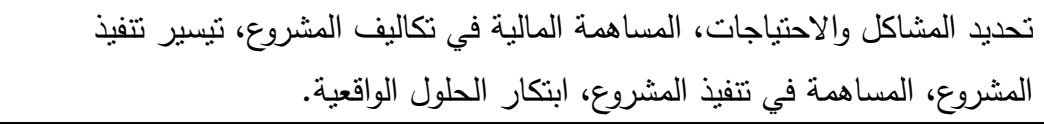 & المجتمعات المحلية \\
\hline 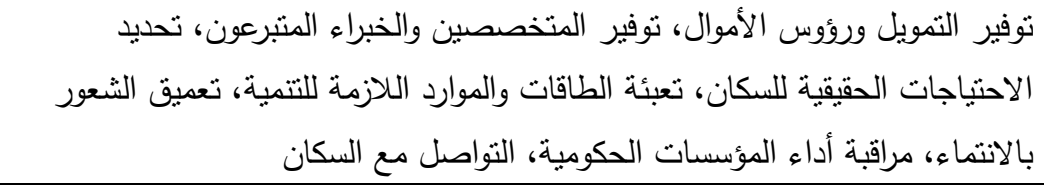 & المنظمات غير الحكومية \\
\hline تحليات الاحتباجات المحلية الاقتصادية والاجتماعية والعمرانية، المساهمة المحدودة في & الجمعيات الأهلية \\
\hline المسئلة السكان على المشاركة، نوعية السكان، بناء جسور الثقة بين الأهالي والجهات & القيادات الثعبية \\
\hline 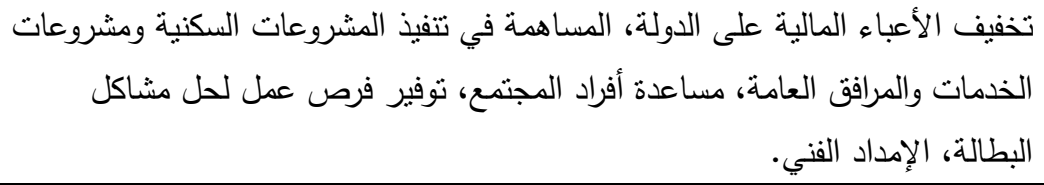 & القطاع الخاص \\
\hline صناعة القرار، المساهمة في حل التعارضات لعملية صناعة القرار ، تمكين المجتمع ومنحه السلطة في & المخطط العمراني \\
\hline تحديد الأولويات وإعداد المخططات بمساهمة المجتمع، تمويل المشروعات، وضع & الجهات المانحة \\
\hline
\end{tabular}


جدول (ץ) : إطار نظري لثركاء التمية وأدوارهم في المراحل المختلفة لمشروعات الارتقاء الحضري

\begin{tabular}{|c|c|c|c|c|c|c|c|c|c|c|c|c|}
\hline \multirow[b]{2}{*}{ والصيانة } & \multicolumn{5}{|c|}{ تنفيذ المشروعات } & \multicolumn{4}{|c|}{ التخطيط والتصديم } & \multicolumn{2}{|c|}{ الإعلان عن المشرع } & \multirow[b]{2}{*}{ الجشاركة } \\
\hline & 里 & 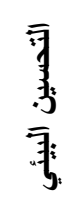 & 承: & $\begin{array}{l}\overline{7} \\
3 \\
\overline{3} \\
\overline{3} \\
\overline{3}\end{array}$ & $\begin{array}{l}\overline{3} \\
\overline{3} \\
\overline{3}\end{array}$ & $\begin{array}{l}\bar{y} \\
\bar{y} \\
\bar{y} \\
\bar{y} \\
\bar{y}\end{array}$ & 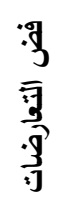 & 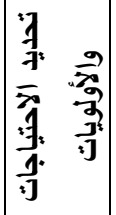 & $\frac{\text { 毣 }}{3}$ & 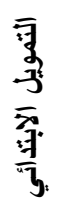 & $\begin{array}{l}\text { 离 } \\
\text { 哥 } \\
\text { 章 }\end{array}$ & \\
\hline $\mathrm{O}$ & & 0 & 0 & 0 & & & $\mathrm{O}$ & $\mathrm{O}$ & $\mathrm{O}$ & 0 & 0 & المكركزية \\
\hline O & $\square$ & 0 & $\square$ & $\Gamma$ & $\mathrm{O}$ & 0 & $\square$ & ○ & 0 & $\mathrm{O}$ & $\mathrm{O}$ & المحلية المكية \\
\hline 0 & 0 & 0 & 7 & 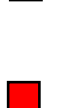 & 0 & 0 & $\mathrm{O}$ & $\square$ & 0 & $\mathbf{X}$ & $\mathbf{X}$ & المحلية \\
\hline $\mathrm{O}$ & 0 & 0 & $\mathrm{O}$ & $\mathrm{O}$ & $\square$ & $\mathrm{O}$ & $\square$ & D & 0 & $\mathbf{X}$ & $\mathbf{X}$ & الحنظمات \\
\hline 0 & & & $\mathrm{O}$ & $\mathrm{O}$ & $\mathrm{O}$ & & 0 & 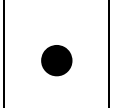 & 0 & $\mathbf{X}$ & $\mathbf{X}$ & الاهميلة \\
\hline 0 & $\mathrm{O}$ & $\mathrm{O}$ & $\mathrm{O}$ & $\mathrm{O}$ & $\mathrm{O}$ & & 0 & 0 & 0 & $\mathbf{X}$ & $\mathbf{X}$ & الثعبية \\
\hline O & 0 & 0 & 0 & 0 & 0 & $\square$ & $\mathbf{X}$ & 0 & $\mathbf{X}$ & $\mathbf{X}$ & $\mathbf{X}$ & الخاص القطاع \\
\hline $\mathrm{O}$ & & & L & & & 0 & 0 & 0 & 0 & $\mathbf{X}$ & $\mathbf{X}$ & العخطط \\
\hline $\mathrm{O}$ & 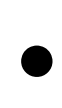 & 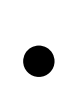 & 0 & 0 & 0 & & $\mathbf{O}$ & & $\mathrm{O}$ & 0 & $\mathbf{X}$ & الجهات \\
\hline
\end{tabular}

مشاركة قوية

• مؤشرات وأسس تحديد شركاء التنمية وأدوارهم بمشروعات الارتقاء الحضري

تتشمل منظومة الثراكة الفاعلة جميع الأطراف المهتمة بمشروع الارتقاء الحضري مثل الحكومة المركزية والمحليـات والجهـات المانحـة (الدوليــة والمحليـة) والمجتمعـات المحليــة والقيـادات الثـعبية والأهليـة

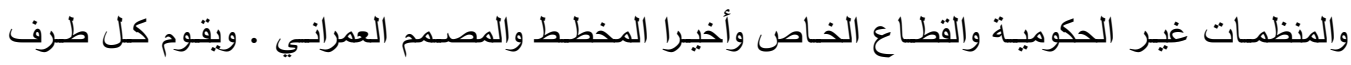


بالمشاركة وفقاً لإمكاناته وقدراته والتي قد لا تتوافر في باقي أطراف المنظومـة، وبالتالي يمكن تحقيق

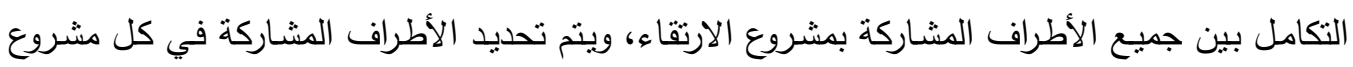

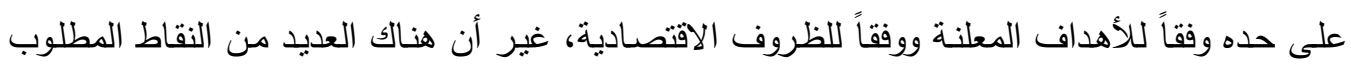

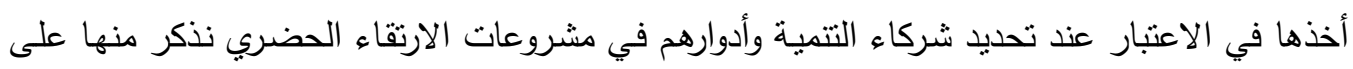

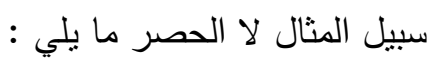
- ضرورة التحديد الدقيق لجميع مراحل المشروع (بدءاً من مرحلة الإعلان عن المشروع ونهاية بالصيانة والمتابعة) وتحديد الأطراف المشاركة والدور المنوط لكل منها. إنشراك القوى الاقتصادية (القطاع الخاص، المنظمات غير الحكومية...إلخ) في تمويل وإدارة

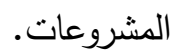

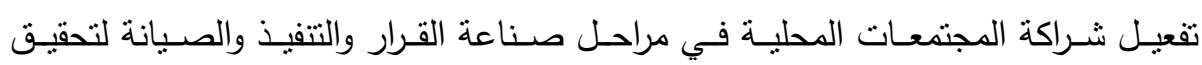
الاستدامة النقافية والبيئية والاقتصادية. ضرورة وجود وسبط mediator ومسـهل facilitator يساعد على استمرارية الحوار بين الأقطاب المختلفة وتمكين المجتمعات ومنحهم السلطة empowerment والمساهمة في حل

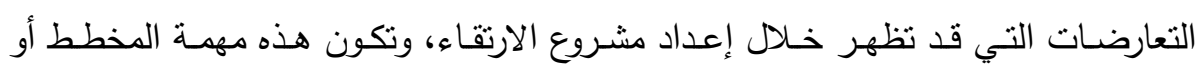

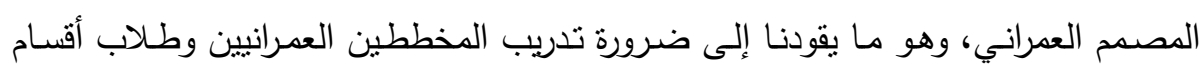

العمارة والتخطيط العمراني على مهارة التفاوض وحل التعارضات بين الأطراف المختلفة.

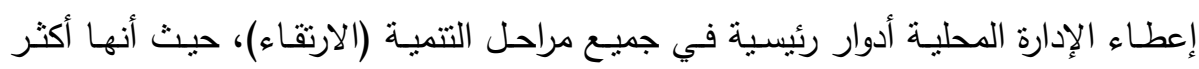
الجهات قدرة على تكوين قاعدة المعلومات عن الأوضاع الراهنة وتحديد الاحتباجات الملحة الأدية

للمجتمع.

احترام التظظيمات المجتمعية القائمة ودعمها من خلال تأسيس جمعيات تتمية المجتمع التي

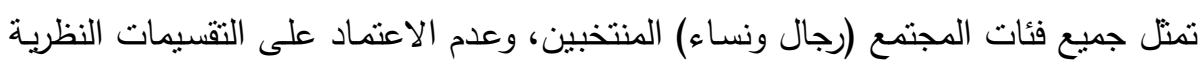
التي قد تفرز مجالس مجتمعية community councils لا تعبر عن المجتمع الحقيقي.

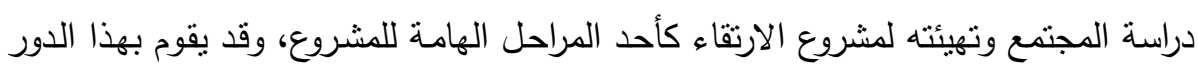
المخطط العمراني أو المتخصصين والخبراء بالمنظمات الحكومية. تكليف الجمعيات الأهلية بالمهام التي لا تحتاج لموارد مالية كبيرة مثل توعية السكان، فتح الفصول التنقيفية للسيدات والفتيات...إلخ. - - الاستفادة من المؤسسات الأكاديمية في وضع المخططات بمستوياتها المختلفة.

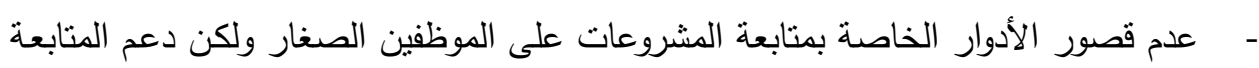
بإسنادها للجهات الإدارية العليا مثل رئيس مجلس المدينة أو حتى محافظ الإقليم. 
- - - استغلال طاقات الثباب في أعمال التتمية وفقاً لتخصصاتهم وإمكانياتهم، مثل إشراك طلبة

كليات الهندسة والفنون الجميلة في الأعمال الفنية، وطلبة الزراعة في عمليات التشجير .

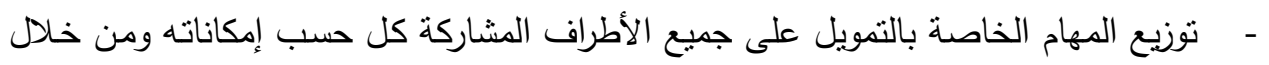
استخدام آليات تضمن استرداد تكاليف المشروعات.

\section{الملاحظات وإلمراجع - - اجع}

1- - شبكة، شاهدان، فاعلية برامج تتمية المجتمعات الفقيرة في تحقيق الاستدامة، المؤتمر العربي

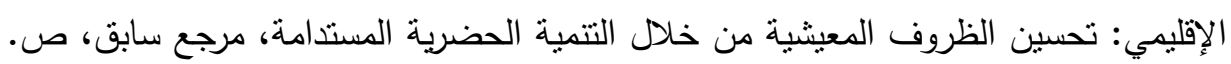

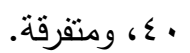

r- - الإكيابي، محمود عبد الهادي وآخرون، تكامل القطاعات المختلفة في عملية التتمية العمرانية للمدينة العربية، ندوة دور القطاع الخاص في تتمية المدن العربية، المعهد العربي لإنماء المدن،

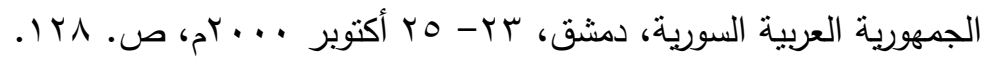

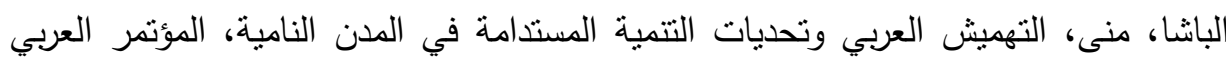
$-4$ الإقليمي: تحسين الظروف المعيشية من خلا التتمية الحضرية المستدامة، مرجع سابق،

$$
\text { ص.919. الباشا، منى، ، مرجع سابق، ص. . .r. }
$$

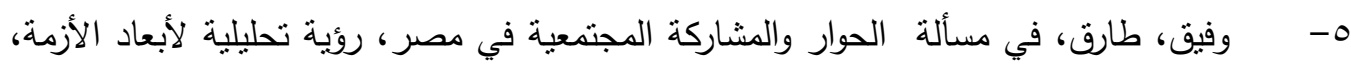

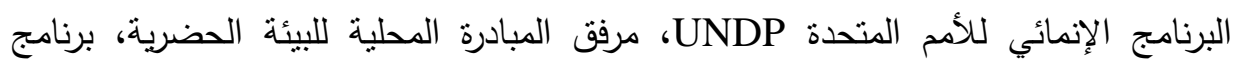

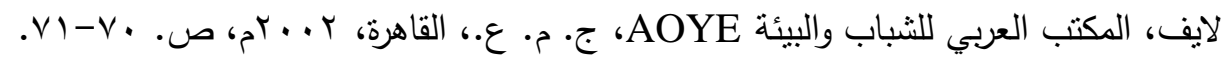

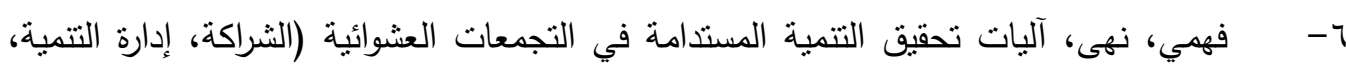
البحوث الإجرائية)، المؤتمر العربي الإقليمي: تحسين الظروف المعيشية من خلاد التنمية

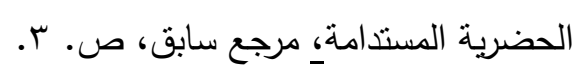

V- - مدبولي، مصطفى، تمكين المشاركة بين القطاعين العام والخاص والاشتراك المباشر للقطاع

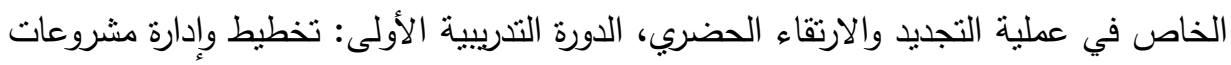

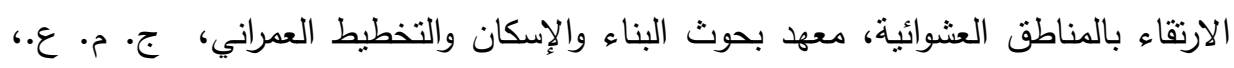

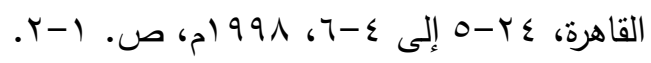

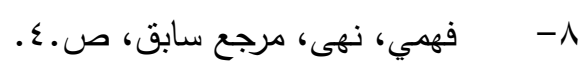

9- ل لمزيد من التفاصيل عن مستويات الثراكة، أنظر المرجع التالي: وفيق، طارق، مرجع سابق،

$$
\text { ص. ص. }
$$


• ا- كامل، رويدة وآخرون، الإدارة المحلية ودور المجتمع في منظومة عمليات التتمية العمرانية المتواصلة، المؤتمر العربي الإقليمي: تحسين الظروف المعيشية من خلال التتمية الحضرية

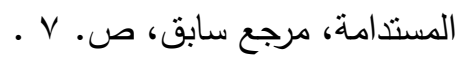
1ا- المشندي، منى صالح، المشاركة الثعبية ودورها في النطوير والإرتقاء بالمناطق العشوائية، المؤتمر العربي الإقليمي: تحسين الظروف المعيشية من خلال التتمية الحضرية المستدامة، ودئة

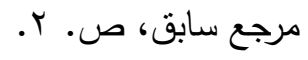

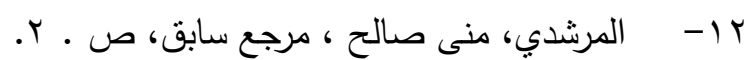

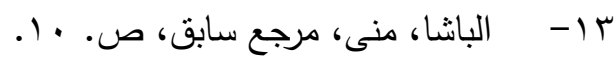

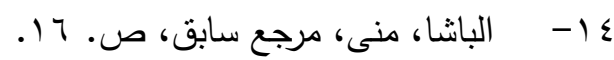

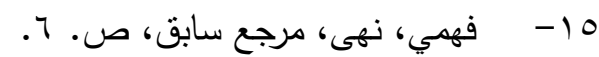

17- مدبولي، مصطفى، المشاركة الثعبية في عملية التجديد والارتقاء الحضري، الدورة التدريبية

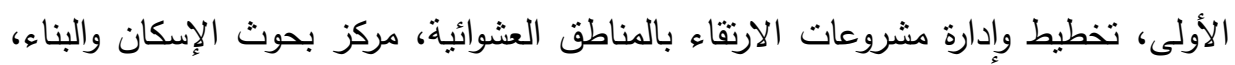

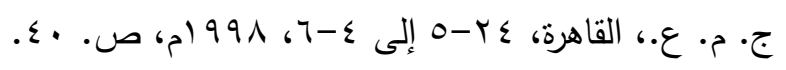

17- Abdel-ghany, Ahmed (1995). Participatory Planning and Contingency Analysis: A Proposed Methodology for Participatory Planning in Urban Upgrading Projects, Unpublished Ph.D. Dissertation, Cairo University, pp. 22-26.

1/- مدبولي، مصطفى، دور المنظمات غير الحكومية في تدعيم وتتمية المجتمعات العمرانية

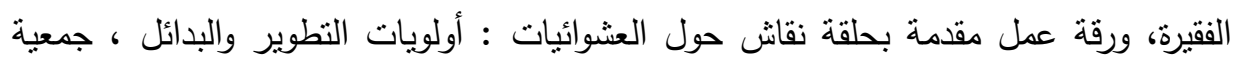

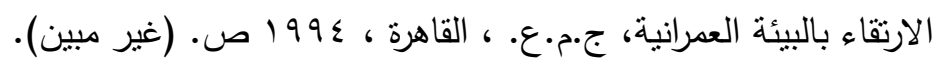

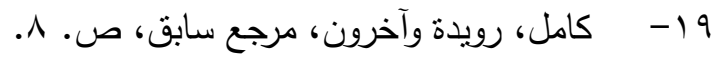

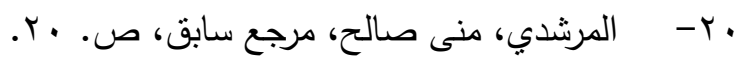

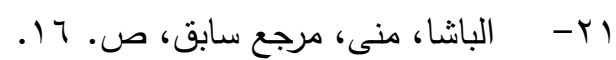

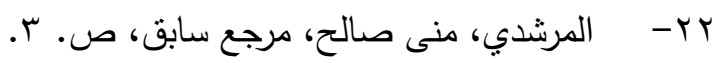

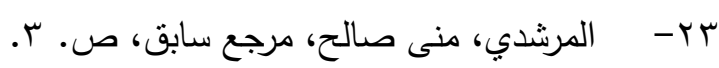

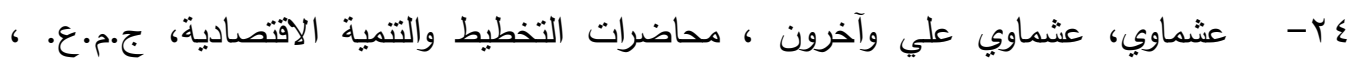

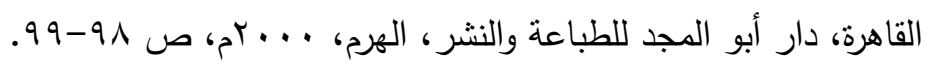

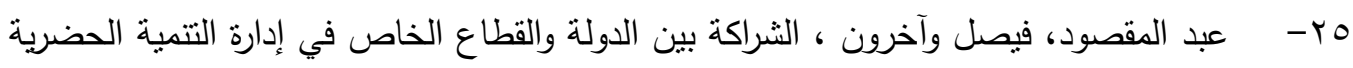

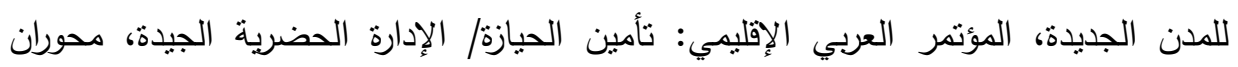


لتحقيق عدالة اجتماعية في المدينة، الهيئة العامة للتخطيط العمراني، ج. م. ع، القاهرة،

$$
.1 \cdot 9.9 .9
$$

26- Said, Nagia, The Role of the Planner as an Advocate and Mediator for the Public Interest, Planning Education in the 21st. Century: Past Experience and Future Responses Symposium, Faculty of Urban \& Regional Planning, Cairo University, Egypt, Cairo, April 26-28, 1999. p. 440.

27- Kamel, Basil, The Role of the Architect in Developing a More Sustainable Community: the Architect as an Enabler, Cairo International Conference: Improving the Living Environment for the Urban Poor, Preparatory Meeting to HABITAT II, The Society for Upgrading the Built Environment, Egypt, Cairo, 18-21 December, 1995. p. 135.

28- Kamel, Basil, Ibid, pp. 139-141

$$
\text { 9 - الباشا، منى، مرجع سابق، ص. r. }
$$

30- Yousry, Ahmed, Participatory Planning Between Theory and Practice: The Case of Nasria Upgrading Project, Cairo International Experience: Improving the Living Environment for the Urban Poor, Cairo, 18-20 Dec. 1995, pp.70-81.

اب- جمعية تتمية المجتمع بالناصرية - أسوان، تتمية المجتمعات الحضرية الفقيرة، الملتقى العربي

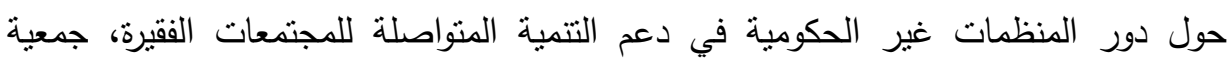

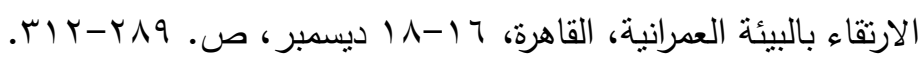

$$
\text { r r- - مسالة ماجستير الارتقاء والمشاركة }
$$

ع ז- أحمد، كامل عبد الناصر، آليات التحسين العمراني وأثرها على التتمية الثاملة، المؤتمر العربي

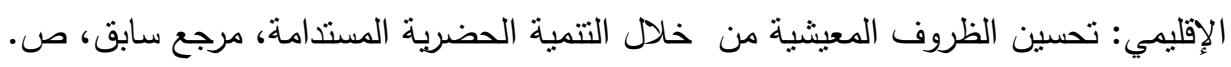

\section{.$\varepsilon$}

هب- لمزيد من التفاصيل عن مشروع التتمية الثاملة لمدينة قنا، أنظر المرجع النالي: أحمد، كامل

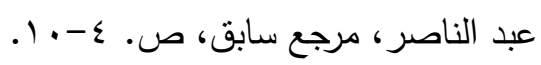

